\begin{tabular}{|c|c|c|}
\hline Beitr. Ent. & Berlin & ISSN 0005-805X \\
\hline $\mathbf{4 8}(1998) 2$ & S. $293-342$ & 05.10 .1998 \\
\hline
\end{tabular}

\title{
A revision of Othius STEPhens - V. The species of the Himalayan region
}

\section{(Coleoptera: Staphylinidae, Xantholininae)}

With 21 figure plates and 2 maps

\section{VOLKER ASSING}

\section{Summary}

The accessible types and further material of Himalayan Othius STEPHENS are revised. 24 species are recognized, 12 of which are described for the first time: $O$. extraordinarius sp. n. (India: HimachalPradesh), O. sinuosus sp. n. (Karakoram), O. infestus sp. n. (East Nepal), O. acifer $\mathbf{s p} . \mathbf{n}$. (East Nepal), O. conifer sp. m. (East Nepal), O. truncatus sp. n. (East Nepal), O. clavifer sp. n. (East Nepal), O. virgifer sp. n. (East Nepal), O. corniger sp. n. (East Nepal), O. longicuneatus sp. n. (Central Nepal), $O$. jaegeri sp. n. (Central Nepal), and $O$. schawalleri sp. m. (Central Nepal). The following new combinations and synonymies are established: Othius nepalensis (SCHEERPELTZ, 1976), comb. n. (transferred from Othiogeiton), and Othius STEPHENS, 1829 = Othiogeiton SCHEERPELTZ, 1976, syn. n. Lectotypes are designated for Othius apicalis CAMERON, 1926, Othius flavocaudatus CAMERON, 1926, and Othius ruficornis CAMERON, 1928. The diagnoses include drawings of the genitalia and further distinguishing characters; they are complemented by comments on the distribution and bionomics of the species. A key allowing identification of the Himalayan representatives of Othius is provided.

\section{Key words}

Coleoptera - Staphylinidae - Xantholininae - Othiini - Othius - Palaearctic - Himalaya - distribution ecology - taxonomy - revision - new species - lectotype designation - new synonym - key to species

\section{Zusammenfassung}

Die zugänglichen Typen und weiteres Material der Gattung Othius STEPHENS aus dem Himalaya werden revidiert. 12 von insgesamt 24 Arten werden neu beschrieben: $O$. extraordinarius sp. n. (Indien: Himachal-Pradesh), O. sinuosus sp. n. (Karakorum), O. infestus sp. n. (Ostnepal), O. acifer sp. n. (Ostnepal), $O$. conifer sp. n. (Ostnepal), O. truncatus sp. n. (Ostnepal), O. clavifer sp. n. (Ostnepal), O. virgifer $\mathbf{s p .}$. n. (Ostnepal), O. corniger $\mathbf{s p .}$. (Ostnepal), O. longicuneatus sp. n. (Zentralnepal), O. jaegeri sp. n. (Zentralnepal), und $O$. schawalleri sp. n. (Zentralnepal). Othiogeiton nepalensis SCHEERPELTZ, 1976 wird der Gattung Othius STEPHENS zugeordnet; Othiogeiton SCHEERPELTZ, 1976 wird damit Synonym von Othius STEPHENS, 1829. Für Othius apicalis CAMERON, 1926, Othius flavocaudatus CAMERON, 1926 und Othius ruficornis CAMERON, 1928 werden Lektotypen designiert. Die Differentialdiagnosen der Arten werden, soweit möglich, durch Abbildungen der Genitalien und weiterer Unterscheidungsmerkmale und durch Angaben zur Verbreitung und Bionomie ergänzt. Für die Othius-Arten des Himalaya-Gebietes wird eine Bestimmungstabelle vorgelegt. 


\section{Introduction}

With the Western Palaearctic species of Othius STEPHENS recently revised (AssING, 1997; in press, and references therein), the present paper represents the fifth contribution to a worldwide revision of the genus. Altogether 11 species have been described from the southern Himalayan region, five of them (O. apicalis, O. flavicornis, O. ruficornis, O. monticola, O. kashmirica) by CAMERON (1926, 1928, 1943), and another five (O. deharvengi, O. yusmargensis, O. cachemiricus, O. pokharensis, O. perreaui) by COIFFAIT (1982a, b; 1983, 1984). SCHEERPELTZ (1976a, b) described a further species $(O$. loeffleri) and a new genus of Othiini including one new species (Othiogeiton nepalensis).

The species of the Himalayan region are here revised before any other group of Eastern Palaearctic Othius, not only because more species have been described from this than from other areas of the Eastern Palaearctic, but also because an interpretation and safe identification - not to mention assessing the systematic and phylogenetic affiliations - of the species was virtually impossible. There have been neither a synopsis nor a key, apart from that in CAMERON (1932), which only accounts for the three species known at that time. In addition, several of the descriptions, particularly the ones by COIFFArT, lack references to similar or related species from the region, and six descriptions were explicitly based on $q q$ (though in two of these cases, the $q q$ fortunately proved to be $\delta \delta$ ). Moreover, with the exception of a rough sketch of the aedeagus of $O$. pokharensis CoIfFArr, the diagnoses available lack any reference whatsoever to the genitalia of the species.

\section{Material and acknowledgements}

Type and further material from the following institutions and private collections was examined:

$\begin{array}{ll}\text { BMNH } & \text { The Natural History Museum, London (M. BRENDELL) } \\ \text { IRSNB } & \text { Institut Royal des Sciences Naturelles de Belgique, Bruxelles (D. DRUGMAND) } \\ \text { IZI } & \text { Institut für Zoologie der Universität Innsbruck (W. SCHEDL) } \\ \text { MHNG } & \text { Muséum d'Histoire Naturelle, Genève (I. LöBL) } \\ \text { MNHNP } & \text { Muséum National d'Histoire Naturelle, Paris (N. BERTI) } \\ \text { NHMB } & \text { Naturhistorisches Museum Basel (M. BRANCUCCI, E. SPRECHER) } \\ \text { NHMW } & \text { Naturhistorisches Museum Wien (H. SCHILLHAMMER) } \\ \text { SMNS } & \text { Staatliches Museum für Naturkunde in Stuttgart (W. SCHAWALLER) } \\ \text { SMTD } & \text { Staatliches Museum für Tierkunde Dresden (O. JÄGER) } \\ \text { cAss } & \text { author's private collection } \\ \text { cFra } & \text { Private collection H. FRANZ, Mödling } \\ \text { cRou } & \text { Private collection G. DE ROUGEMONT, London } \\ \text { cSme } & \text { Private collection A. SMETANA, Ottawa }\end{array}$

I am grateful to the colleagues who kindly arranged the loan of types and further material, without which this study would not have been possible.

\section{Measurements}

The measurements in the descriptions and the key are indicated in $\mathrm{mm}$ and abbreviated as follows:

HW: $\quad$ maximal head width

HL: $\quad$ head length from front margin of clypeus to neck

PW: maximal width of pronotum 
PL: $\quad$ length of pronotum along median line

EL: $\quad$ length of elytra from apex of scutellum to elytral hind margin

TiL: length of metatibiae (external aspect, from knee to insertion of first metatarsomere)

TaL: $\quad$ length of metatarsi (claws not included)

TL: $\quad$ total length from apex of mandibles to hind margin of tergum VIII.

\section{The Himalayan species of Othius}

\section{Othius apicalis CAMERON, 1926}

Figs 1 a - h, Map 1 (p. 298)

Othius apicalis CAMERON, 1926: 347

\section{Types examined}

Lectotype đ, here designated: Chakrata Dist., Chulli Khud, 6500/ Dr. Cameron, 20.V.22/ M. Cameron Bequest. B. M. 1955-147./ Syntype/ Lectotypus Othius apicalis Cameron, desig. V. Assing 1998 (BMNH).

Paralectotypes, here designated and labelled accordingly: 1 \% , same labels as lectotype (MHNG); 16, Type [round curator label]/ Arni Gad, Mussoorie., Dr. Cameron, 13.IV.22/ Othius apicalis Cam. Type./ M. Cameron Bequest. B. M. 1955-147./ Syntype (MHNG).

\section{Additional material examined}

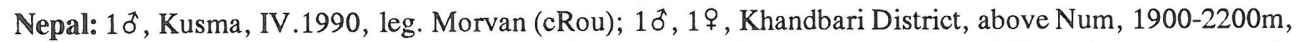
23.IV.1984, leg. Smetana \& Löbl (MHNG, cSme); 10, Khandbari District, Arun Valley at Num main bridge, 1050m, 22.IV.1984, leg. Smetana \& Löbl (cSme); 10, Prov. Bagmati, Dobate Ridge NE Barahbise, 2800m, 2.V.1981, leg. Löbl \& Smetana (cAss); 10, Nepal, Kosi, Basantpur, 2300m, 30.V.2.VI.1985, leg. Holzschuh (cAss).

Sikkim: 2 $\uparrow$, Gopaldhara, Rungbong Valley, leg. Stevens (BMNH).

India: $1 \hat{0}$, Kumaun, Haldwani District, leg. Champion (BMNH); 19 , Kumaun (UP), Kathgodam near Haldwani, 600m, 6.X.1979, leg. Löbl (MHNG); 10, Ghum District, moss, V.-VI.1931, leg. Cameron (BMNH); 10`, Meghalaya, Khasi Hills, Shillong, 1850-1950m, 25.X.1978, leg. Besuchet \& Löbl (cAss).

\section{Diagnosis}

Measurements (range, arithmetic mean; $\mathrm{n}=15$ ): HL: $1.65-1.83,1.85$; HW: $1.59-1.83,1.70$; PW: $1.71-1.92,1.81$; PL: $2.01-2.29,2.18$; EL: $1.52-1.71,1.62$; TiL: $0.78-0.88,0.83$; TaL: $0.66-0.71,0.70$; TL: $10.1-14.3,11.96$.

Colour of body blackish brown to black with the posterior $1 / 5$ of abdominal segment VII, the posterior $1 / 3$ of segment VIII and the terminalia yellowish to reddish brown; appendages brown to blackish brown.

Head as wide as long or nearly so, HL/HW: $1.00-1.06$ (mean: 1.03), and slightly narrower than the pronotum, HW/PW: $0.89-0.98$ (mean: 0.94 ); eyes relatively large, $0.45-0.60 \mathrm{x}$ the length of postgenae in lateral view; temples behind eyes usually weakly dilated, rarely \pm parallel in dorsal view; dorsal surface shiny, with extremely fine and shallow microsculpture, which is predominantly composed of short transverse meshes; micropunctation minute and sparse; macropunctation absent in median, coarse and \pm sparse in lateral and posterior area; frons with posterior pair of punctures absent, the anterior punctures situated in \pm roundish impressions and accompanied by 0-2 additional punctures; frontal furrows shallow, but distinct. Pronotum weakly dilated anteriorly, $1.14-1.23 x$ (mean: 1.20) longer than wide; posterior median scratch-like impression often very small; dorsal surface very shining, without microsculpture (though indistinct traces of microsculpture may be present near anterior margin); posterior discal puncture near hind angles (Fig. 1g). 

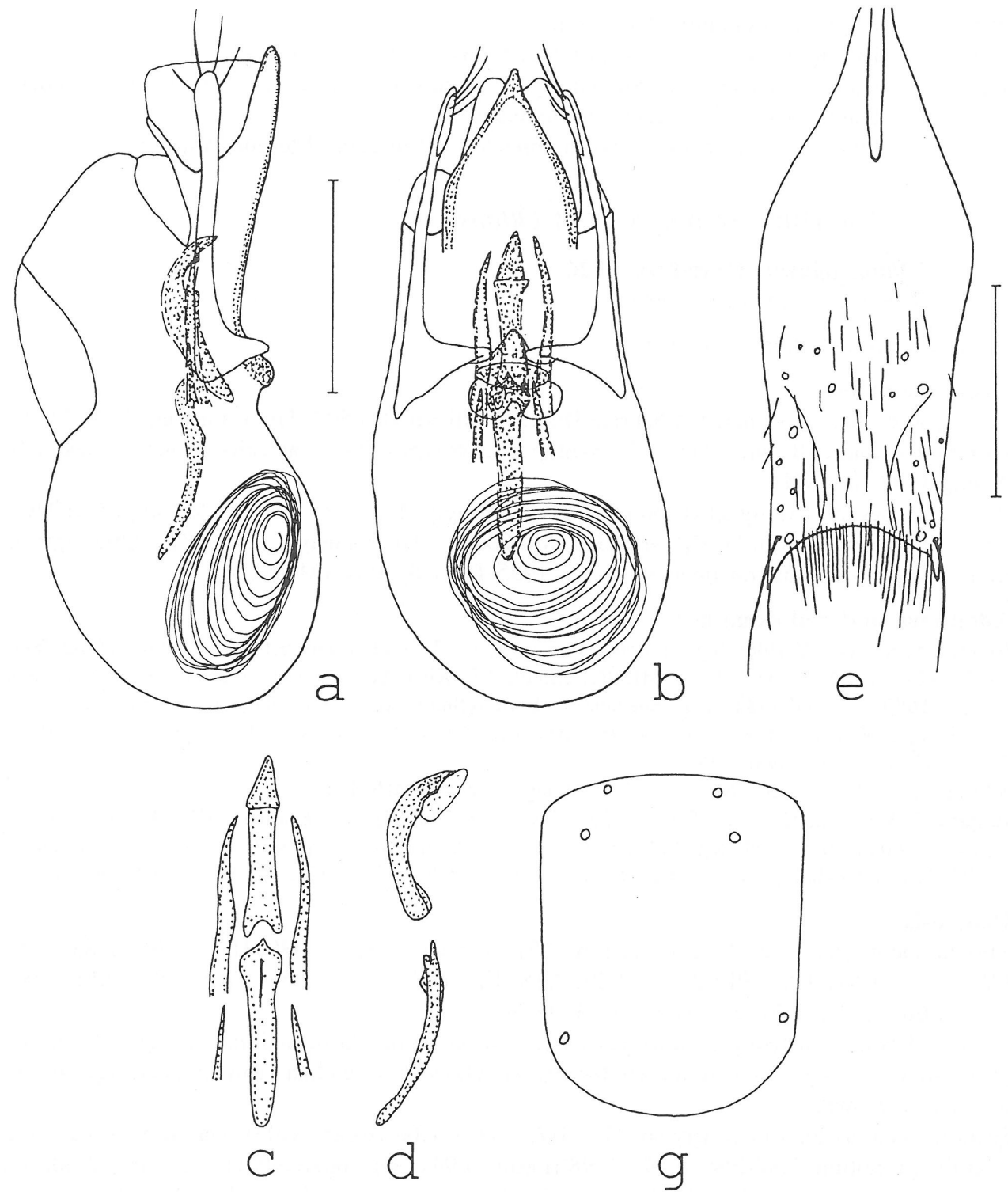

Fig. 1: O. apicalis CAMERON (e, f: LT; h: PLT): aedeagus in lateral (a) and in ventral view (b); sclerotized internal structures in ventral view (c); median internal structures in lateral view (d); $\delta$ sternum IX (e); schematic representation of variability (left - right) of position of pronotal punctures (g); setae partly omitted in $\mathrm{e}-\mathrm{h}$. Scales: $0.5 \mathrm{~mm}$ (g without scale).

Elytra relatively long (EL/PL: 0.69 - 0.78, mean: 0.74); punctures deep, well-defined, rather dense and \pm evenly spaced; microsculpture absent; hind wings apparently fully developed; scutellum with distinct microsculpture, with some large, but not very deep punctures, often with interspersed smaller punctures; legs relatively long and slender; TiL/TaL: $1.13-1.24$, mean: 1.19 . 

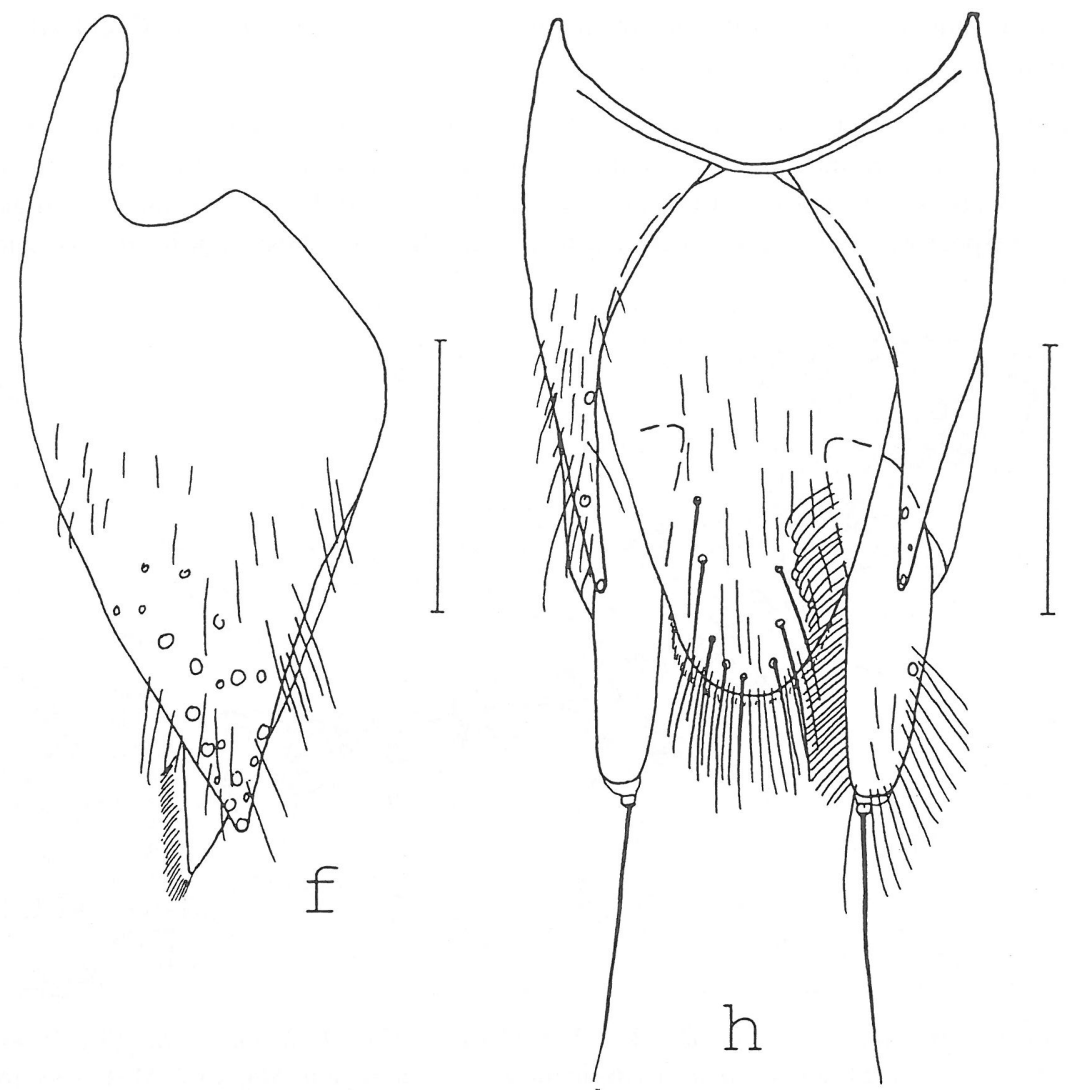

Fig. 1: O. apicalis CAMERON (e, f: LT; h: PLT): $\widehat{o}$ lateral tergal sclerite IX and tergum $\mathrm{X}$ in lateral view (f); i terminalia (h).

Abdomen with moderately dense punctation, punctures on tergum VII distinctly finer than on the anterior terga; microsculpture near anterior margins of terga distinct and \pm isodiametric, on remainder of tergal surface transverse, very fine and shallow; surface (especially of tergum VII) often with somewhat iridescent shine; palisade fringe on hind margin of tergum VII present.

$\delta$ : protarsi distinctly dilated; sternum VII with hind margin weakly concave and posterior median area with dense long pubescence; hind margin of sternum VIII \pm truncate to weakly convex; hind margin of sternum IX \pm broadly and deeply concave, hind angles acutely dentate, posterior median area with not very dense, long and yellowish pubescence (Fig. 1e); lateral tergal sclerites IX acute and with one terminal seta (Fig. 1f); ventral process of median lobe rather broad and apically acute, without distinct median carina; parameres apically dilated; internal sac with 6 distinctly sclerotized structures: a long and apically characteristically enlarged median basal, a large and in lateral view hook-shaped median apical, a pair of shorter oblong, and a pair of long lateral pieces; flagellum thin and with more than 30 coils (Figs $1 \mathrm{a}-\mathrm{d}$ ).

\%: protarsi somewhat less dilated than in $\delta$, but sexual dimorphism not very pronounced; hind margin of sternum VIII weakly convex, almost truncate (similar to $O$. flavocaudatus, cf. Fig. $3 \mathrm{~h}$ ), and with rather dense row of relatively long yellowish setae; hind margin of tergum $\mathrm{X}$ broadly convex, posterior setae long and unmodified; styli rather short, their inner margin with fringe of numerous long and apically bent setae (Fig. 1h). 
Comparative notes: For distinction from the similar $O$. pokharensis CoIfFArT and $O$. extraordinarius sp. $\mathrm{n}$. see below those species.

Comments: CAMERON (1926) based his description on more than one specimen without indicating the precise number or designating a holotype. Therefore, the three specimens in the Cameron collection from the localities indicated in the original description must be regarded as syntypes, irrespective of the labels attached to them. The $\delta$ in best condition was selected as lectotype.

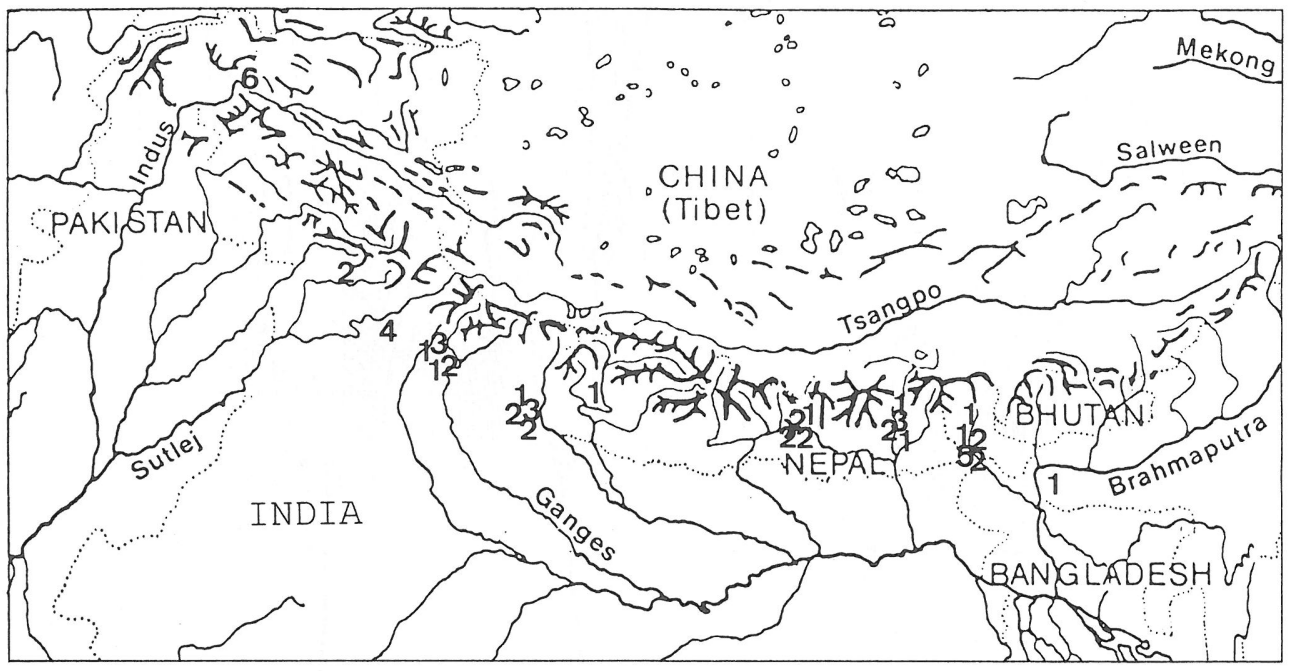

Map 1: Known distribution of $O$. apicalis (1), O. pokharensis (2), O. flavocaudatus (3), O. extraordinarius (4), $O$. monticola (5), and $O$. sinuosus (6) in the Himalayan region. Map by J. MARTENS, modified.

Distribution and bionomics: The known distribution of $O$. apicalis ranges from Kumaun (central northern India) in the west to Sikkim and Meghalaya (northeastern India) in the east (Map 1). The examined specimens were collected at lower to intermediate altitudes (600 $2800 \mathrm{~m}$ ) in spring (April through June) and autumn (October).

Othius pokharensis COIFFAIT, 1983

Figs 2 a - f, Map 1

Othius pokharensis COIFFAIT, 1983: $163 \mathrm{f}$

\section{Type material}

According to the original description, which is based on a single $\delta$, the holotype is deposited in the collection of H. Franz, Mödling. Material from this collection is at present inaccessible (SCHILlHAMMER, pers. comm.), so that it was not possible to study the holotype. The original description, however, indicates important external characters and includes a drawing of the aedeagus, both of which are in good agreement with the material listed below, which also includes specimens from central Nepal and on which the following diagnosis is based. Judging from the size of the eyes, the length of the elytra and hind wings, and the presence of the palisade fringe, species is polymorphic, but in principle capable of flight, so that a wider distribution can be assumed. 

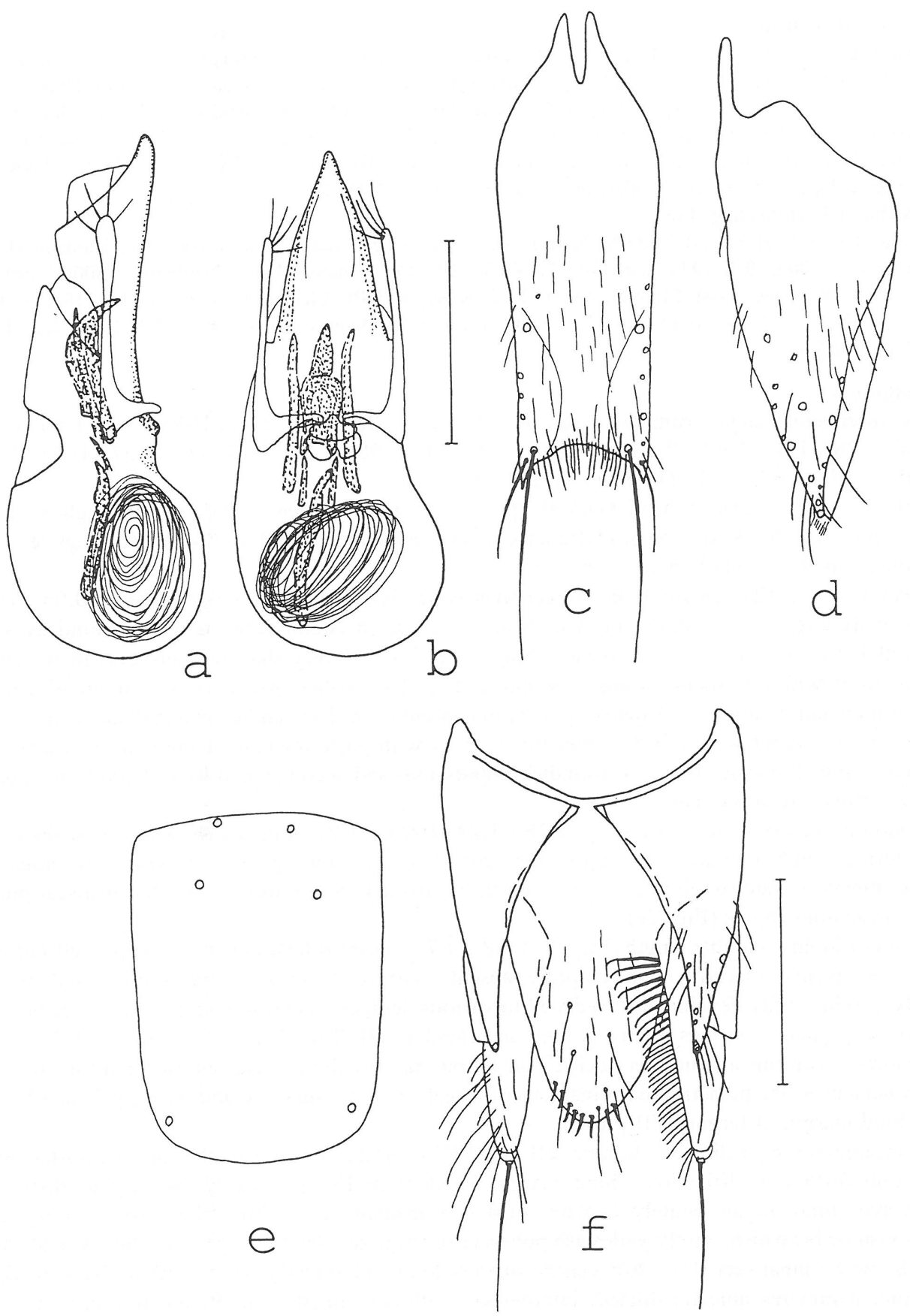

Fig. 2: $O$. pokharensis CoIFFAIT: aedeagus in lateral (a) and in ventral view (b); $\widehat{\delta}$ sternum IX (c); $\delta$ lateral tergal sclerite IX and tergum X in lateral view (d); schematic representation of variability (left - right) of position of pronotal punctures (e); + terminalia (f); setae partly omitted in $\mathrm{c}-\mathrm{f}$. Scales: $0.5 \mathrm{~mm}$ (e without scale). 


\section{Material examined}

Nepal: East: $3 \delta \delta$, Sankhua Sabha District, Arun Valley between Mure and Hurure, mixed broad-leaved forest, 2050-2150m, 9.-17.VI.1988, leg. Martens \& Schawaller (SMNS, cAss); 10, Mure Num, 1500$1900 \mathrm{~m}, 25 . V .1980$, leg. Wittmer (NHMB). Central: 1\%, Shermatang, Malemche Bridge, leg. Franz (NHMW); 10े, Dinguari Khola, Trisuli Basar, IX.-X.1971, leg. Franz (cAss); 2むð, 19, Lalitpur Distr., 2km S Godavari, 1700m, 20.X.1983, leg. Smetana \& Löbl (MHNG, cAss); 19 , Lalitpur Distr., Phulcoki, northern slope, 2600m, 16.X.1983, leg. Smetana \& Löbl (MHNG).

Sikkim: $1 \delta^{\pi}$, Darjeeling (IRSNB).

India: $1 \delta^{\pi}, 1$, Himachal-Pradesh, Katrain near Kulu, leg. Franz (cFra, cAss); 1 \%, Kumaun (UP), Ramgarh, 2000m, 9.X.1979, leg. Löbl (MHNG); 10, 19, Kumaun (UP), Chaubattia, 1800m/1900m, 12.-14.X.1979, leg. Löbl (MHNG, cAss); 2 $\%$, Kumaun (UP), Chaubattia near Ranikhet, 1800m, 12.13.X.1979, leg. Löbl (MHNG); 10ै, 19, Garhwal (UP), Mussoorie, 1700m, 19.X.1979, leg. Löbl (MHNG, cAss).

\section{Diagnosis}

Measurements (range, arithmetic mean; $\mathrm{n}=20$ ): HL: 1.28 - 1.53, 1.41; HW: $1.16-1.46,1.31$; PW: 1.28 - 1.50, 1.42; PL: 1.55 - 1.83, 1.72; EL: 0.98 - 1.23, 1.13; TiL: 0.57 - 0.70, 0.65; TaL: $0.47-0.57,0.53$; TL: $8.2-11.2,9.36$.

Colour variable, usually head blackish, pronotum and abdomen, except for the lighter apex, dark brown to blackish brown, elytra dark brown, antennae reddish to brown, and legs ferrugineous; sometimes whole body \pm brown.

Head 1.02 - 1.12x (mean: 1.08) longer than wide, HW/PW: 0.87 - 0.98 (mean: 0.93); eyes relatively large, $0.38-0.56 \mathrm{x}$ the length of postgenae in lateral view; temples behind eyes \pm parallel in dorsal view; dorsal surface shiny, with fine and very shallow transverse microsculpture, often with interspersed transverse and isodiametric meshes, particularly so in anterior half; micropunctation minute and sparse; punctation absent in median, and coarse and sparse in lateral area; near occiput with only few punctures; frons with posterior pair of punctures present, the anterior punctures situated in \pm roundish impressions and accompanied by $0-2$ additional punctures; frontal furrows shallow.

Pronotum weakly dilated anteriorly, 1.18 - 1.27x (mean: 1.22) longer than wide; in median line posteriorly with a scratch-like impression; dorsal surface shining, usually with very indistinct fine transverse microsculpture, rarely with more distinct microsculpture; posterior discal puncture near hind angles (Fig. 2e).

Elytra of highly variable length (EL/PL: 0.58 - 0.75, mean: 0.66); punctures deep, well-defined and \pm evenly spaced; microsculpture absent, surface therefore very shiny; hind wings polymorphic, fully developed or reduced to various degrees; scutellum with some large, but not very deep punctures; legs relatively long and slender; TiL/TaL: $1.13-1.28$, mean: 1.23.

Abdomen with fine and not very dense punctation; microsculpture near anterior margins of terga distinct and \pm isodiametric, on remainder of tergal surface transverse and weak; palisade fringe on hind margin of tergum VII present.

$\delta$ : protarsi strongly dilated; sternum VII and VIII truncate to very weakly concave posteriorly, without further modifications; hind margin of sternum IX \pm broadly, weakly to distinctly concave, hind angles acutely dentate, posterior median area with rather sparse, long and blackish or brownish, rarely yellowish pubescence (Fig. 2c); lateral tergal sclerites IX acute and with one terminal seta (Fig. 2d); ventral process long and apically acute, without basal median carina; parameres apically dilated; internal sac with 6 distinctly sclerotized structures: a long median basal, a large and in lateral view hook-shaped median apical, a pair of small oblong, and a pair of long lateral pieces; flagellum thin and with ca. 25-30 coils (Figs 2a, b).

$\%$ : protarsi dilated, but distinctly less so than in 0 ; hind margin of sternum VIII weakly convex and with rather dense row of relatively long yellowish setae; tergum $\mathrm{X}$ broad and posteriorly 
with moderately long and apically weakly curved modified setae; inner margin of styli with fringe of numerous long, in anterior region very stout and apically bent setae (Fig. 2f).

Comparative notes: Among the Himalayan congeners, $O$. pokharensis is most similar to $O$. apicalis, from which it is readily distinguished by the smaller size, the presence of a posterior pair of frontal punctures on the head, the more distinct microsculpture of the pronotum, and by the of sexual characters.

Distribution and bionomics: $O$. pokharensis is apparently the most widely distributed species of Othius in the southern Himalaya, its known distribution ranging from Himachal-Pradesh in the west to Sikkim in the east (Map 1), where it has been collected at intermediate altitudes (ca. $1700-2600 \mathrm{~m})$.

\section{Othius flavocaudatus CAMERON, 1926}

Figs 3 a - h, Map 1 (p. 298)

Othius flavocaudatus CAMERON, 1926: 346

\section{Types examined}

Lectotype $\delta$, here designated: Chakrata Dist., Sijla Gad, 5000// Dr. Cameron, 12.V.22/ M. Cameron Bequest. B. M. 1955-147./ Lectotypus Othius flavocaudatus Cameron, desig. V. Assing 1998 (BMNH).

Paralectotype, here designated: 1\%: Chakrata Dist., Sijla Gad, 5000', Dr. Cameron, 12.V.22/ 6/ Othius flavocaudatus Cam., Type/ M. Cameron Bequest. B. M. 1955-147./ Paralectotypus Othius flavocaudatus Cameron, desig. V. Assing 1998 (BMNH).

\section{Additional material examined}

Nepal: $2 \hat{\delta} \hat{\delta}, 3 q q$ [partly teneral], Khandbari District, Arun Valley at Num main bridge, $1150 \mathrm{~m}$, 21.IV.1984, leg. Smetana \& Löbl (cSme, cAss).

India: 1 \%, Kumaun (UP), W. Almora, 19.V., leg. Champion (BMNH).

\section{Diagnosis}

Measurements (range; $\mathrm{n}=8$ ): HL: 1.83 - 2.04; HW: 1.65 - 1.83; PW: 1.62 - 1.80; PL: 1.95 2.14; EL: 1.40 - 1.53; TiL: $0.71-0.79$; TaL: $0.56-0.59$; TL: $9.6-12.3$.

Colour characteristic: head, antennae, pronotum and abdomen brown to dark brown, legs usually light brown; the elytra, the posterior $1 / 5$ of abdominal segment VII, all of segment VIII and the terminalia yellowish to reddish yellow.

Head large, $1.07-1.17 \mathrm{x}$ longer than wide and usually at least slightly wider than pronotum (HW/PW: $1.00-1.05$ ); eyes relatively large, $0.37-0.48 x$ the length of postgenae in lateral view; temples behind eyes \pm parallel in dorsal view; dorsal surface with fine microsculpture predominantly composed of transverse striae; micropunctation rather indistinct, minute and sparse; macropunctation \pm sparse in lateral and posterior area, almost extending to the middle of dorsal surface; frons with posterior pair of punctures absent, the anterior punctures situated in \pm roundish impressions and accompanied by 0-2 additional punctures; frontal furrows shallow, but distinct.

Pronotum weakly dilated anteriorly, $1.19-1.26 x$ longer than wide; posterior median scratchlike impression of variable length; dorsal surface with distinct, but shallow transverse microsculpture; discal punctation pattern similar to $O$. apicalis, but posterior discal puncture nearer to hind angles (Fig. 3f). 

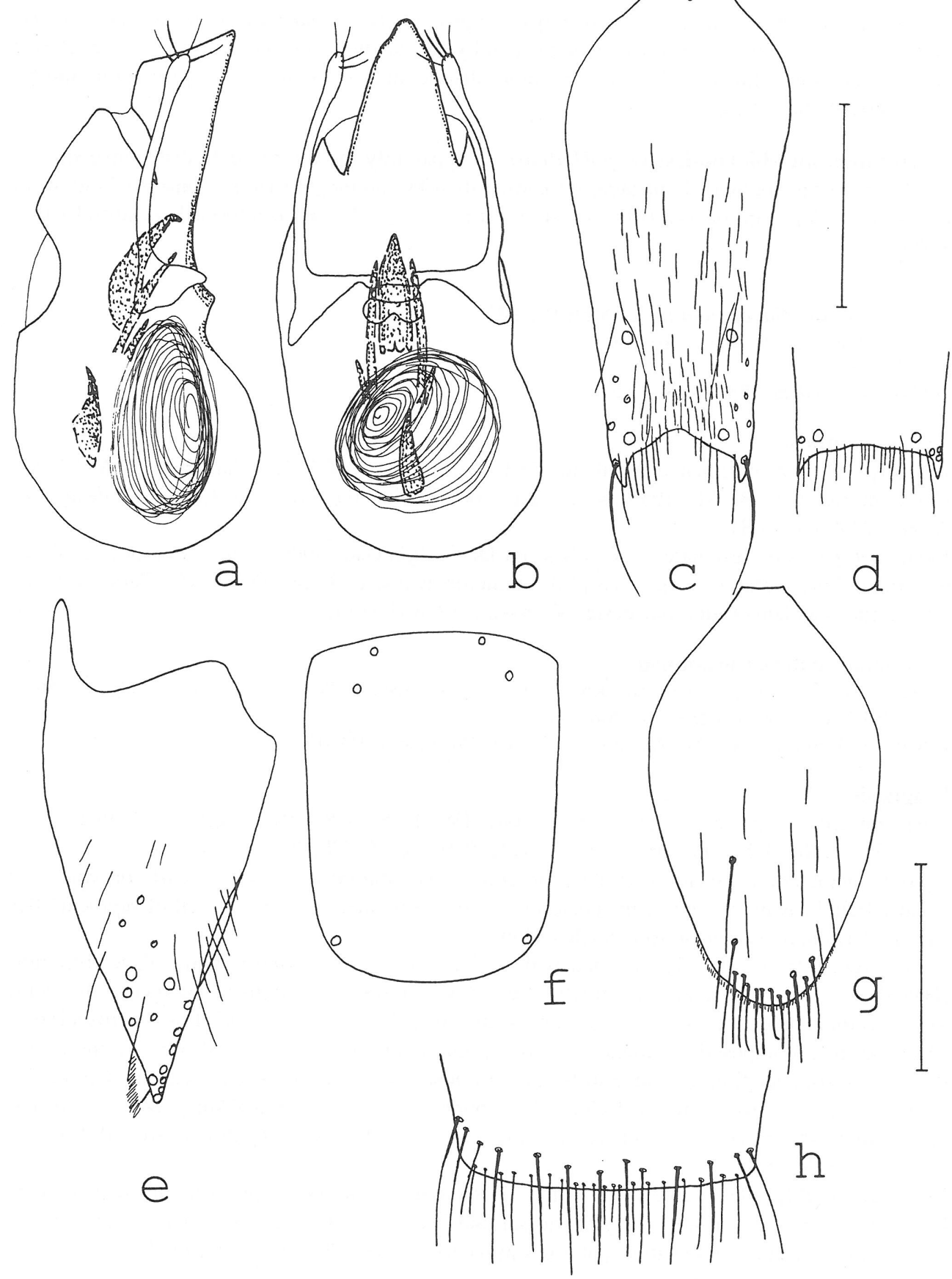
Elytra relatively long (EL/PL: 0.68 - 0.74); punctures deep, well-defined and \pm evenly spaced, less dense than in $O$. apicalis; microsculpture indistinct, composed of extremely minute and not very dense micropunctation, surface therefore slightly less shiny than in $O$. apicalis; hind wings apparently fully developed; scutellum with distinct isodiametric microreticulation and usually with some large, but not very deep punctures; tarsi shorter than in $O$. apicalis; TiL/TaL: $1.24-1.37$.

Abdomen with punctation and microsculpture similar to $O$. apicalis; palisade fringe on hind margin of tergum VII present.

$\delta$ : protarsi strongly dilated; sternum VII with hind margin weakly concave, without further modifications; hind margin of sternum VIII centrally weakly concave; concavity of hind margin of sternum IX \pm broad and of variable depth, hind angles acutely dentate, posterior median area with rather dense and short, yellowish pubescence (Figs 3c, d); lateral tergal sclerites IX acute and with one terminal seta, tergum X relatively short (Fig. 3e); ventral process of median lobe less broad and apically less acute than in $O$. apicalis, without distinct median carina; parameres apically weakly dilated; internal sac with 6 sclerotized structures: an apically acute median basal, a larger and in lateral view apically bent and acute median apical, a pair of short oblong, and a pair of long lateral pieces; flagellum thin and with ca. 25-30 coils (Figs 3a, b).

$\$$ : protarsi as dilated as in $\delta$; hind margin of sternum VIII almost truncate, and with rather dense row of relatively long yellowish setae (Fig. 3h); hind margin of tergum X broadly convex, posterior setae long and weakly modified: rather stout, but apically not distinctly bent (Fig. 3g); styli rather short, their inner margin with fringe of numerous long and apically bent setae.

Comparative notes: $O$. flavocaudatus is readily distinguished from its Himalayan congeners based on external characters alone. From the related larger species with a palisade fringe and shining elytra (O. apicalis, $O$. pokharensis, $O$. extraordinarius), it is separated especially by the characteristic coloration, the more massive head and the $\delta$ sexual characters.

Comments: In his original description, CAMERON (1926) neither specified the number, nor did he designate a holotype. Of the two syntypes in the Cameron collection, the $\delta$ was selected as lectotype.

Distribution and bionomics: Apart from the type locality in Northern India, the species has become known only from a further locality in Kumaun and from eastern Nepal (Map 1). Like $O$. apicalis, it apparently occurs at lower to intermediate altitudes. Several specimens collected in April and May were teneral.

Othius extraordinarius sp. $\mathrm{n}$.

Figs 4 a - b, Map 1 (p. 298)

Holotype $q:$ N-INDIEN Himach.Pr., Umg. Kufri, ca. 2600m, 16.-17.7.1989, lg. Hiermeier $(18,20,22)(\mathrm{NHMW})$.

\section{Diagnosis:}

Measurements (HT): HL: 2.29; HW: 2.17; PW: 2.17; PL: 2.53; EL: 2.01; TiL: 0.93; TaL: 0.72; TL: 15.3 .

Fig. 3: O. flavocaudatus CAMERON (a - c, e: LT): aedeagus in lateral (a) and in ventral view (b); $\delta$ sternum IX (c); hind margin of sternum IX of further $\delta$ (d); $\delta$ lateral tergal sclerite IX and tergum X in lateral view (e); schematic representation of variability (left - right) of position of pronotal punctures ( $f$ ); $q$ tergum X (g); hind margin of $q$ sternum VIII $(\mathrm{h})$; setae partly omitted in $\mathrm{c}-\mathrm{f}$, h. Scales: $0.5 \mathrm{~mm}$ (f without scale). 


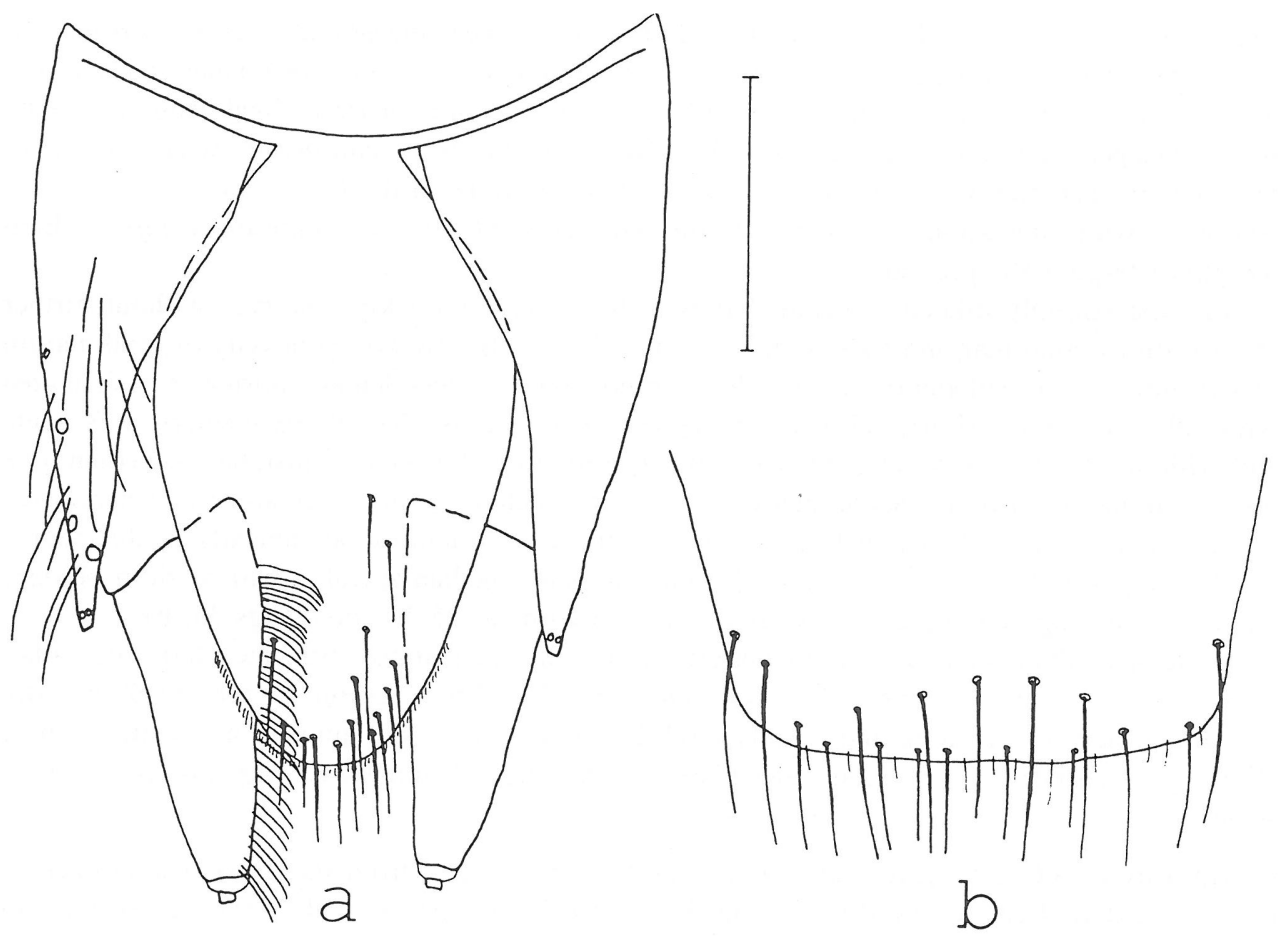

Fig. 4: 0 . extraordinarius sp. n. (HT): $q$ terminalia (a); hind margin of $\$$ sternum VIII (b); setae partly omitted. Scale: $0.5 \mathrm{~mm}$.

Body, except for the dark brown tarsi and external face of the protibia, completely black. Head oblong, 1.06x longer than wide, and as wide as pronotum; eyes relatively large, $0.45 \mathrm{x}$ the length of postgenae in lateral view; temples behind eyes dilated in dorsal view; dorsal surface with very shallow, almost indistinct fine microsculpture predominantly composed of transverse striae; with scattered, indistinct micropunctation; macropunctation in lateral and posterior area moderately dense, almost reaching the middle of dorsal surface; frons with posterior pair of punctures absent, the anterior punctures both situated in a transverse impression and each accompanied by 1-2 additional punctures; frontal furrows shallow.

Pronotum distinctly dilated anteriorly, $1.17 \mathrm{x}$ longer than wide; posterior median scratch-like impression minute; most of dorsal surface without microsculpture and therefore very shiny, traces of transverse striae present in anterior 1/4; discal punctation pattern similar to $O$. apicalis (only right posterior puncture present in holotype!).

Elytra relatively long (EL/PL: 0.80 ); punctation as in $O$. apicalis, but slightly less dense and less large; microsculpture composed of minute and rather dense micropunctation, which is more distinct than in $O$. flavocaudatus, surface therefore with reduced shine; hind wings apparently fully developed; scutellum with distinct microreticulation and some large, though shallow punctures; legs relatively long and slender; TiL/TaL: 1.25.

Abdomen with microsculpture similar to $O$. apicalis, but punctation finer and somewhat less dense than in that species; palisade fringe on hind margin of tergum VII present. o: unknown. 
$:$ protarsi strongly dilated; hind margin of sternum VIII weakly convex, and with row of long black setae with interspersed short yellowish setae (Fig. 4b; hind margin of tergum X broadly convex, posteriorly with numerous long black, unmodified setae; styli rather short, their inner margin with fringe of numerous long and apically bent setae (Fig. 4a).

Derivatio nominis: The name (lat.: extraordinary, exceptional) not only refers to the characteristic size and colour of the species, but also to the fact that, in spite of his original intentions never to base a description of a species of Othius on a single female, the author could not resist the temptation to make an exception in this case.

Comparative notes: $O$. extraordinarius is easily distinguished from the other Himalayan Othius species by size alone. Among the related, at least potentially macropterous species, it is in addition characterized by the dark colour, the microsculpture of the elytra and the chaetotaxy of the terminalia.

Distribution and bionomics: The species is only known from the type locality in HimachalPradesh, northwestern India (Map 1), where it was collected at an altitude of $2600 \mathrm{~m}$. Its external morphology (eye size, length of elytra and probably hind wings, presence of a palisade fringe) indicate that it may be more widely distributed in the region.

Othius monticola CAMERON, 1943

Figs 5 a - f, Map 1 (p. 298)

Othius monticola CAMERON, 1943: 128

Type examined

Holotype đơ [teneral]: Type [round curator label]/ Ghum dist., Tiger Hill, 8,500-10,000 ft., vvi-1931, Dr. Cameron/ O. monticola Cam., Type/ M. Cameron Bequest, B. M. 1955-147/ Holotype ơ, Othius monticola Cameron, rev. V. Assing 1998 (BMNH).

\section{Additional material examined}

1 [teneral], same data als holotype, but without Cameron's type label (BMNH).

\section{Diagnosis}

Measurements (HT, non-type specimen): HL: 1.46, 1.56; HW: 1.28, 1.46; PW: 1.43, 1.56; PL: 1.75, 1.89; EL: 1.13, 1.13; TiL: 0.63, 0.65; TaL: 0.50, 0.53; TL: 9.4, 11.0.

Of similar size and general appearance as $O$. pokharensis. Colour in the two teneral specimens dark brown, with the elytra, legs and basal antennomeres lighter, yellowish to light brown.

Head $1.06-1.14 x$ longer than wide, narrower than the pronotum (HW/PW: $0.89-0.94)$; eyes relatively large, $0.36-0.40 \mathrm{x}$ the length of postgenae in lateral view; temples behind eyes \pm parallel or weakly dilated in dorsal view; dorsal surface with fine microsculpture predominantly composed of transverse striae; micropunctation very indistinct, scattered punctures visible only in anterior half of dorsal surface; macropunctation \pm sparse in lateral area, only few punctures present near occiput; frons with posterior pair of punctures absent, anterior punctures without additional punctures; anterior impressions and furrows very shallow.

Pronotum weakly dilated anteriorly, $1.22 \mathrm{x}$ longer than wide; posterior median scratch-like impression not very pronounced; dorsal surface with distinct, but shallow and fine transverse microsculpture, therefore less shiny than in $O$. pokharensis; discal punctation pattern similar to O. apicalis, but posterior discal puncture slightly more distant from the lateral margin.

Elytra relatively long (EL/PL: $0.64,0.60)$; punctures of similar size and depth as in $O$. pokharensis, but less dense; microsculpture absent; hind wings apparently reduced; scutellum with distinct microreticulation and some large, but not very deep punctures; TiL/TaL: 1.27, 1.23. 


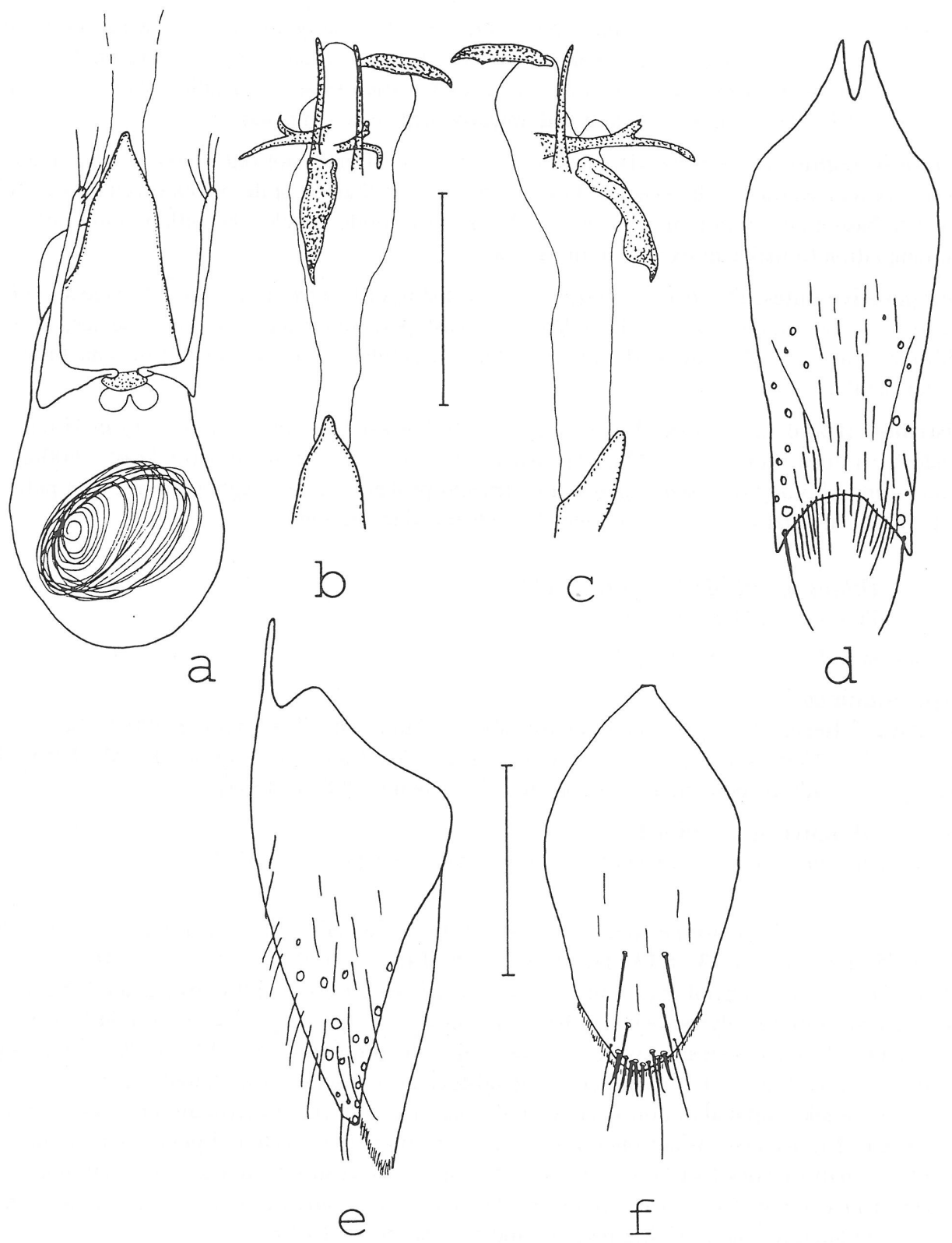

Fig. 5: O. monticola CAMERON (a - e: HT): aedeagus in ventral view (a); internal sac with internal structures in ventral (b) and in lateral view (c); $\hat{o}$ sternum IX (d); $\delta$ lateral tergal sclerite IX and tergum

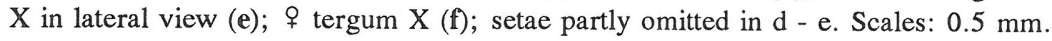

Abdomen with punctation and microsculpture similar to $O$. pokharensis, but punctures less dense; palisade fringe on hind margin of tergum VII absent.

$\delta$ : protarsi strongly dilated; sternum VII with hind margin weakly concave, without further 
modifications; hind margin of sternum VIII \pm truncate; concavity of hind margin of sternum IX \pm broad and deep, hind angles acutely dentate, posterior median area with rather sparse, long and blackish pubescence (Fig. 5d); lateral tergal sclerites IX acute and with one terminal seta, not reaching hind margin of tergum X (Fig. 5e); ventral process of median lobe in ventral view of similar shape as in $O$. pokharensis, without distinct median carina; parameres apically weakly dilated, with relatively long setae; internal sac with 4 sclerotized structures: an apically acute median basal, a larger and in lateral view subapically enlarged median apical, and a pair of long bifid lateral pieces; flagellum thin and with ca. 25-30 coils (Figs $1 \mathrm{a}-\mathrm{c}$ ).

$q$ : protarsi as dilated as in $\delta$; hind margin of sternum VIII convex, and with rather dense row of relatively long yellowish setae; hind margin of tergum $\mathrm{X}$ broadly convex, posterior setae modified, stout, but apically not distinctly bent (Fig. 5f); chaetotaxy of styli similar to $O$. pokharensis.

Comparative notes: $O$. monticola is distinguished from the similar $O$. pokharensis, the only species of similar size and with shining elytra among the Himalayan congeners, by the absence of the posterior pair of frontal punctures and of the palisade fringe on the hind margin of tergum VII, by the sparser punctation of elytra and abdomen and by the $\delta$ sexual characters.

Comments: In his original description CAMERON (1943) only mentions a (singular) "Type in [his] collection". One of the two specimens in the Cameron collection was identified as the holotype, as it carries Cameron's original identification and type label. The second specimen is not referred to in the description and cannot be considered a paratype, although the labels indicate that it was collected together with the holotype.

Distribution and bionomics: The species has become known only from the type locality in Darjeeling, northeastern India (Map 1). Both specimens were teneral and collected in late spring (May/June). The altitude of the type locality as well as the reduction of hind wings and the absence of a palisade fringe suggest that the species is more or less endemic.

Othius sinuosus sp. $\mathrm{n}$.

Figs 6 a - e, Map 1 (p. 298)

Holotype $\delta: ~ \delta / 22 /$ Oesterreichische Karakorum Expedition, leg. Dr. E. Piffl/ HaramoschMassiv, Iskere, Kaltaro Bach, unter Steinen (NHMW).

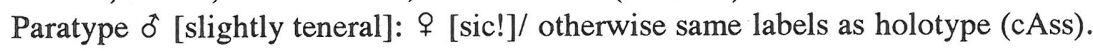

\section{Diagnosis}

Measurements (HT, PT): HL: 1.77, 1.62; HW: 1.71, 1.53; PW: 1.86, 1.62; PL: 2.14, 1.95; EL: $1.53,1.40$; TiL: 0.71, 0.63; TaL: 0.57, 0.54; TL: 12.3, 10.8 .

Colour blackish brown to black, legs dark brown with the tarsi lighter, elytra reddish.

Head of characteristic suboval shape, $1.04-1.06 x$ longer than wide, somewhat narrower than pronotum (HW/PW: 0.92, 0.94); temples behind eyes broadly convex in dorsal view; eyes relatively large, $0.45-0.50 \mathrm{x}$ the length of postgenae in lateral view; dorsal surface with distinct fine microsculpture predominantly composed of transverse striae with interspersed transverse or isodiametric meshes; micropunctation not visible; macropunctation of lateral and posterior area rather dense, almost reaching middle of dorsal surface; frons with posterior pair of punctures absent, anterior punctures situated in \pm roundish impressions (PT) or in one transverse impression (HT), each with 1 - 2 additional punctures; anterior furrows shallow.

Pronotum of characteristic shape, rather short (PL/PW: 1.15, 1.21), weakly dilated anteriorly, and with slightly sinuate lateral margins; posterior median scratch-like impression not very 
pronounced; dorsal surface with distinct, predominantly transverse microsculpture; discal punctation pattern similar to $O$. flavocaudatus, but posterior punctures slightly more distant from hind angles (cf. Fig. 3f).
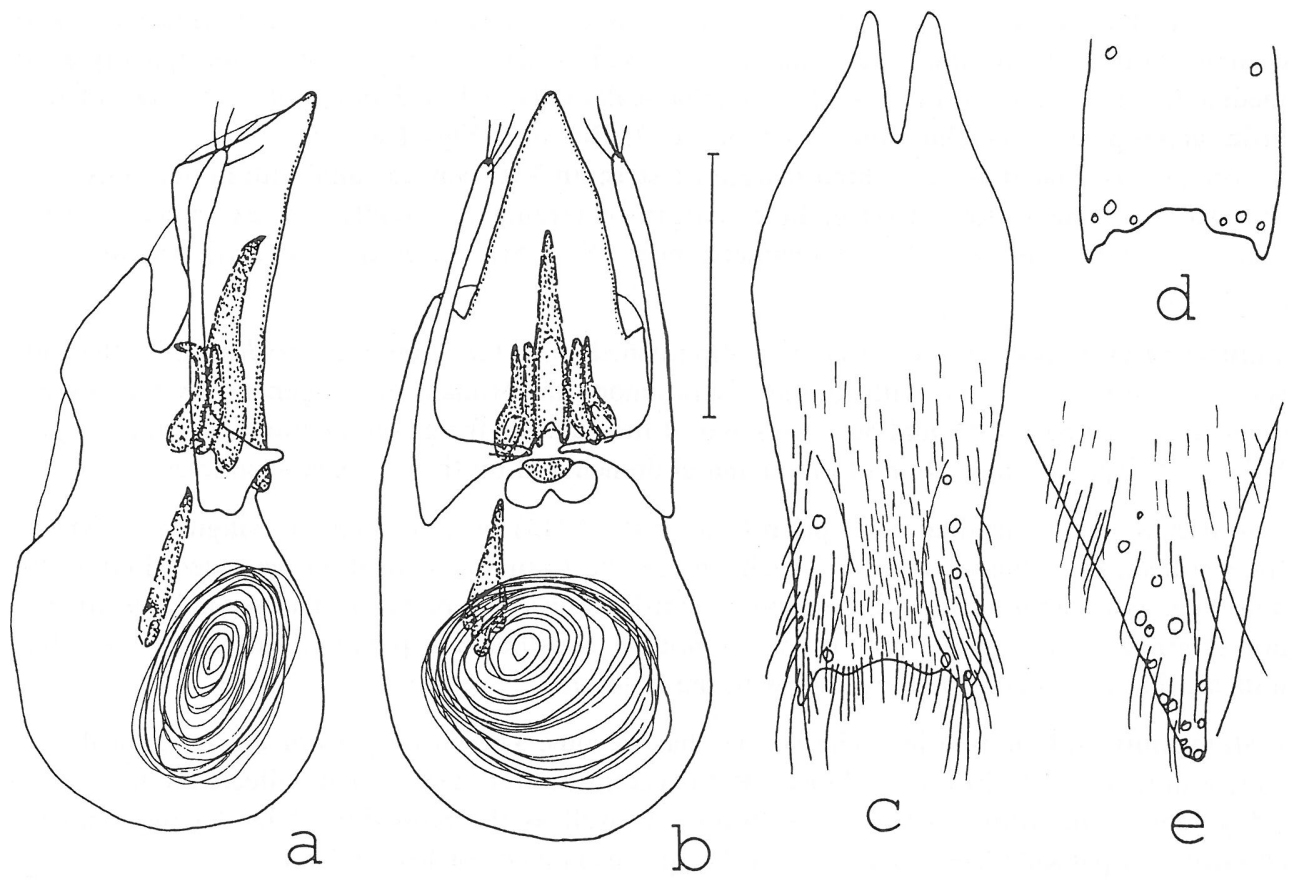

Fig. 6: $O$. sinuosus sp. n.: aedeagus in lateral (a) and in ventral view (b); $\delta$ sternum IX (c); hind margin of sternum IX of HT (d); $\delta$ lateral tergal sclerite IX and tergum X in lateral view (e); setae partly omitted in c-e. Scale: $0.5 \mathrm{~mm}$.

Elytra relatively long (EL/PL: 0.71, 0.72); punctures rather sparse and not very coarse, separated by interstices $2-4 \mathrm{x}$ wider than the punctures; dorsal surface mat due to very distinct and dense micropunctation; hind wings apparently fully developed; scutellum with distinct microreticulation and shallow punctation; TiL/TaL: 1.24, 1.17 .

Abdomen with moderately dense, fine and weakly granulose punctation; microsculpture near anterior margins of terga distinct and reticulate, on remainder of tergal surfaces slightly more shallow, but also composed of isodiametric and short transverse meshes; palisade fringe on hind margin of tergum VII present.

ठ: protarsi strongly dilated; sternum VII with hind margin weakly concave, without further modifications; hind margin of sternum VIII centrally weakly concave; sternum IX posteriorly sinuate, with broadly dentate hind angles, posterior median area with dense, short and yellowish or greyish pubescence, posterior lateral area with numerous dark setae (Fig. 6c, d); lateral tergal sclerites IX acute and with two terminal setae, not projecting beyond hind margin of tergum X (Fig. 6e); median lobe of similar shape as in $O$. pokharensis, ventral process without distinct basal median carina; parameres apically weakly dilated; internal sac with a wedgeshaped median basal, a longer and weakly curved median apical, a pair of rather short oblong, and a pair of hook-shaped lateral pieces; flagellum thin and with ca. 20-25 coils (Figs 6a, b). क: unknown. 
Derivatio nominis: The name (lat.: sinuate) refers to the shape of the lateral margins of the pronotum and of the hind margin of the $\delta$ sternum IX.

Comparative notes: 0 . sinuosus is readily separated from all the Himalayan congeners based on several external characters alone: the shape of the head and the pronotum, the dense micropunctation of the elytra and the microsculpture of the abdomen. In addition it is distinguished by the unique shape of the $\delta$ sternum IX and the internal structures of the aedeagus.

Distribution and bionomics: The species is known only from the type locality south of the Karakoram range (Map 1). Eye size, wing development, and the presence of a palisade fringe indicate that it should be more widely distributed.

\section{Othius ruficornis CAMERON, 1928}

Figs 7 a - $f$

Othius ruficornis CAMERON, 1928: $561 \mathrm{f}$

\section{Type examined}

Lectotype ô, present designation: Type [round curator label]/ Sikkim: Karponang. 10,000 ft, 20.IV.1924, Maj. R. W. G. Hingston./ Everest Exp. Brit. Mus. 1924-386/ O. ruficornis Cam., Type/ Syntype [round curator label]/ Lectotypus oे, Othius ruficornis Cameron, desig. V. Assing 1998 (BMNH).

Paralectotype + , here designated: under stones/ Sikkim: Karponang. 10,000 ft, 20.IV.1924, Maj. R. W. G. Hingston./ Everest Exp. Brit. Mus. 1924-386/ O. ruficornis Cam. / M. Cameron Bequest, B. M. 1955-147/ Syntype [round curator label]/ Paralectotypus $\uparrow$, Othius ruficornis Cameron, desig. V. Assing 1998 (BMNH).

\section{Diagnosis}

Measurements (LT, PLT): HL: 1.95, 1.71; HW: 1.83, 1.59; PW: 1.86, 1.68; PL: 2.26, 2.04; EL: $1.25,1.13$; TiL: $0.83,0.77$; TaL: 0.71, 0.63; TL: 11.2, 11.6.

Colour in the two teneral specimens blackish brown, with the legs and basal antennomeres lighter, reddish to dark brown.

Head slightly longer than wide (HL/HW: 1.07, 1.08), almost as wide as pronotum (HW/PW: $0.98,0.95$ ); eyes relatively small, $0.25-0.30 x$ the length of postgenae in lateral view; temples behind eyes weakly dilated in dorsal view; dorsal surface with distinct fine microsculpture predominantly composed of transverse meshes of variable length; micropunctation not visible; macropunctation moderately dense in lateral and in posterior area, almost reaching middle of dorsal surface; frons with posterior pair of punctures absent, anterior punctures situated in \pm roundish impressions, each with 2 - 3 additional punctures; anterior furrows shallow, but distinct.

Pronotum weakly dilated anteriorly, $1.21-1.22 \mathrm{x}$ longer than wide; posterior median scratchlike impression not very pronounced; dorsal surface \pm mat due to distinct microsculpture, which is composed of transverse meshes and transverse striae; discal punctation pattern similar to 0 . infestus (cf. Fig. 8f).

Elytra relatively short (EL/PL: 0.55 ); punctures sparse, separated by interstices $4-5 \mathrm{x}$ wider than the punctures, rather small, \pm regularly spaced, and partly slightly granulose; dorsal surface mat due to very distinct isodiametric microsculpture; hind wings reduced; scutellum with distinct microreticulation and some large, but not very deep punctures; TiL/TaL: 1.17, 1.21. 

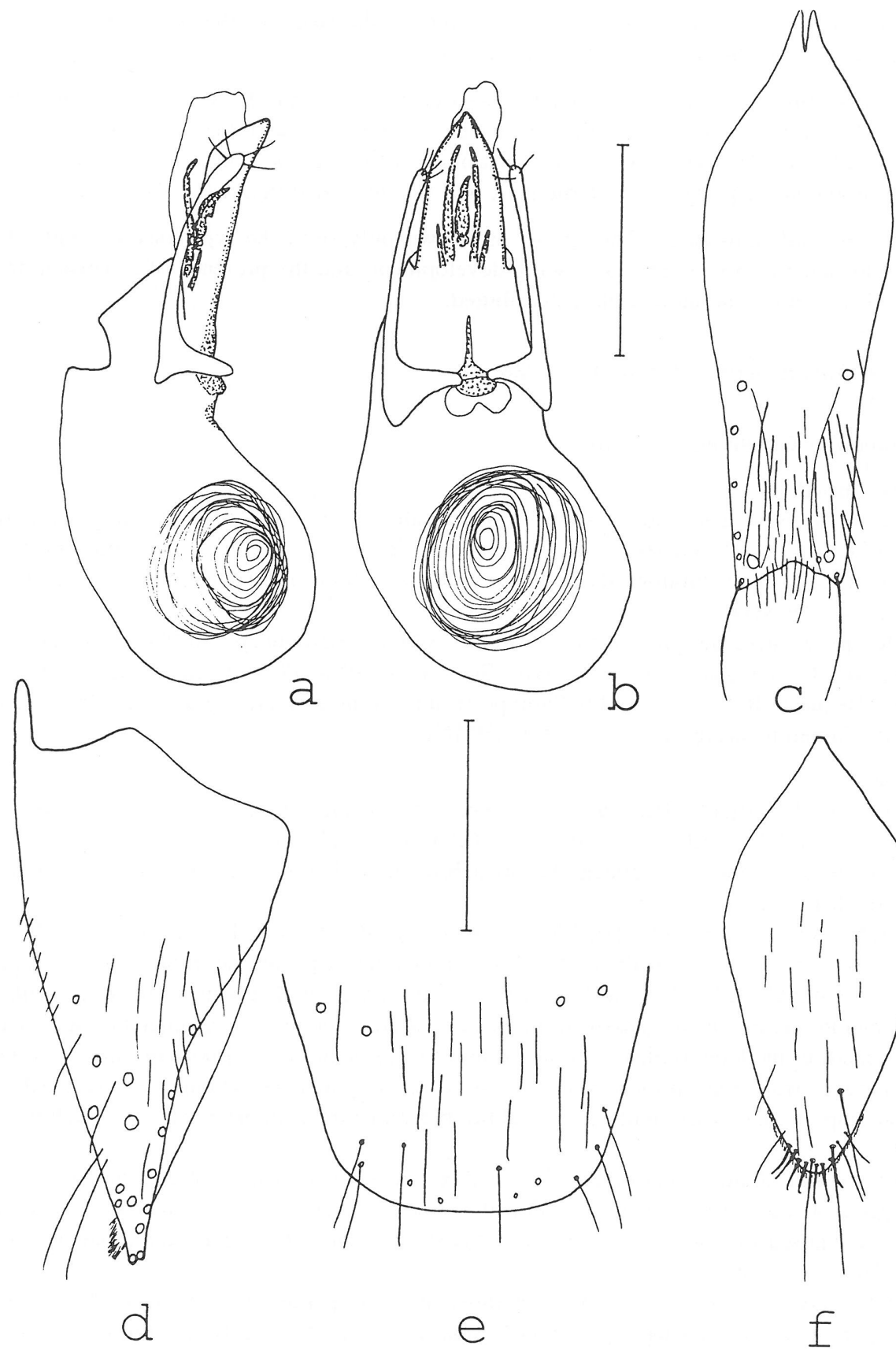
Abdomen with fine and rather sparse punctation; microsculpture near anterior margins of terga distinct and predominantly composed of transverse meshes, on remainder of tergal surfaces very shallow and composed of transverse striae; palisade fringe on hind margin of tergum VII absent. $\delta$ : protarsi strongly dilated; sternum VII with hind margin weakly concave, without further modifications; hind margin of sternum VIII \pm weakly convex (Fig. 7e); concavity of hind margin of sternum IX not very deep, hind angles weakly dentate, posterior median area with moderately dense, long and yellowish pubescence (Fig. 7c); lateral tergal sclerites IX acute and with two terminal setae, slightly projecting beyond hind margin of tergum X (Fig. 7d); median lobe of similar shape as in $O$. infestus and related species, ventral process with basal median carina; parameres apically dilated; internal sac with a median apical, a pair of short oblong, and a pair of very long lateral pieces; basal median structure absent; flagellum thin and with ca. 20-25 coils (Figs 7a, b).

q: protarsi almost as dilated as in $\delta$; hind margin of sternum VIII convex, and with rather dense row of relatively long yellowish setae; hind margin of tergum $\mathrm{X}$ acutely convex, and with moderately stout, and apically weakly bent, modified setae (Fig. 7f); internal face of styli with fringe of numerous long, apically at most weakly curved setae.

Comparative motes: From the Nepalese congeners related to $O$. infestus, with which this species shares the distinct microsculpture of the forebody, especially the microreticulation of the elytra, $O$. ruficornis is distinguished by its larger size and by the $\delta$ sexual characters.

Comments: The original description (Cameron, 1928) is based on "Two $q$ examples". Fortunately, one of the syntypes proved to be a $\delta$, which is here designated as lectotype.

Distribution and bionomics: The species has become known only from the type locality in Sikkim, where the two syntypes were collected in April. Judging from the altitude of the type locality, the reduction of hind wings and the absence of a palisade fringe, and the restricted distribution of the related congeners, $O$. ruficornis is very likely to be endemic to the area.

\section{Othius infestus sp. $\mathrm{n}$.}

Figs 8 a - f, Map 2 (p. 313)

Holotype ठ: NEPAL-Expeditionen Jochen Martens/ 361 Taplejung Distr., upper Simbua Khola Valley, near Tseram, 3250-3350m, mature Abies-Rhododendron forest, 10-15 May 88, J. Martens $\&$ W. Schawaller leg. (SMNS). Paratypes: $10^{\star}, 2 \% \%$, same data as holotype (SMNS, cAss).

\section{Diagnosis}

Measurements (range; $\mathrm{n}=4$ ): HL: 1.28 - 1.37; HW: 1.19 - 1.34; PW: 1.28 - 1.40; PL: 1.59 1.68; EL: 0.85 - 0.92; TiL: $0.50-0.56$; TaL: $0.44-0.47$; TL: $9.2-10.3$.

Colour of body including elytra and appendages blackish brown to black.

Head $1.02-1.08 x$ longer than wide; HW/PW: $0.93-0.98$; eyes small, $0.32-0.38 x$ the length of postgenae in lateral view; temples behind eyes usually distinctly widened in dorsal view; dorsal surface somewhat shiny, but with distinct microsculpture predominantly composed of transverse meshes and transverse striae; micropunctation minute, barely noticeable; punctation absent in median, and coarse and rather dense, in lateral area and near occiput; frons with posterior pair of punctures absent, the anterior punctures situated \pm roundish impressions and accompanied by - in all four type specimens - 2 additional punctures; frontal furrows shallow. Pronotum not or only weakly dilated anteriorly, $1.20-1.27 x$ longer than wide; in median line posteriorly with a scratch-like impression; most of dorsal surface with distinct fine and dense microsculpture composed of long transverse meshes, near anterior margin also of short transverse and isodiametric meshes; posterior discal punctures near hind angles (Fig. 8f). 


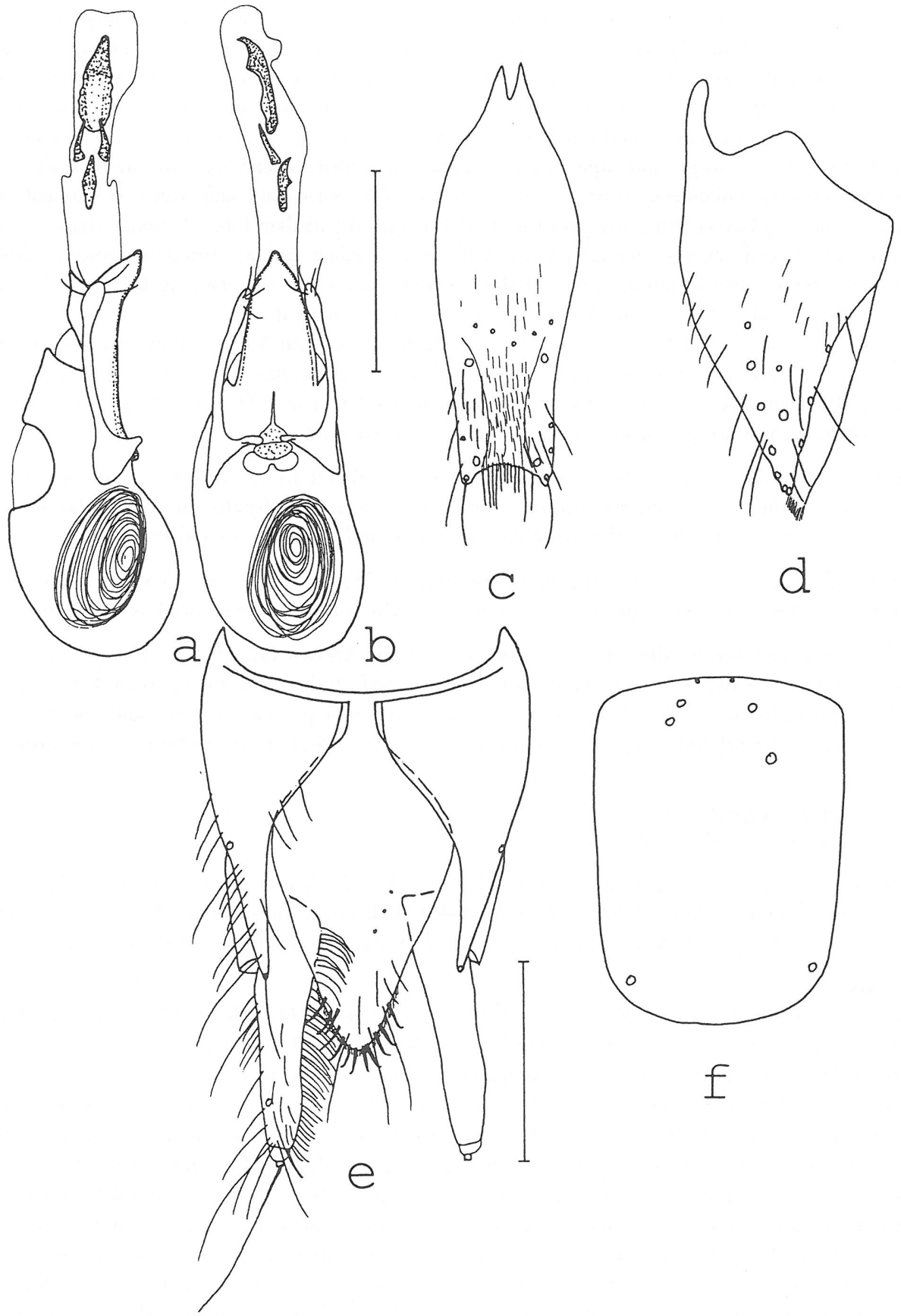

Fig. 8: $O$. infestus sp. n.: aedeagus in lateral (a) and in ventral view (b); $\delta$ sternum IX (c); $\delta$ lateral tergal sclerite IX and tergum $X$ in lateral view (d); $\uparrow$ terminalia (e); schematic representation of variability (left - right) of position of pronotal punctures (f); setae partly omitted in c - e. Scales: $0.5 \mathrm{~mm}$ (f without scale). 
Elytra short, EL/PL: 0.54 - 0.55; punctures rather large, but shallow, irregularly spaced, often partly confluent, surface therefore somewhat uneven; surface mat due to dense microreticulation; hind wings reduced; legs relatively long and slender; TiL/TaL: 1.13 - 1.23.

Abdomen more shining than forebody; punctation sparse and fine; microsculpture near anterior margins of terga composed of \pm transverse meshes and distinct, on remainder of tergal surfaces transverse and very weak; palisade fringe on hind margin of tergum VII absent.

$\delta$ : protarsi distinctly dilated in both sexes, only slightly more so in $\delta \delta^{*}$ than in $q q$; sternum VII truncate to very weakly concave posteriorly, without further modifications; sternum VIII with \pm truncate hind margin, pubescence rather sparse and long; hind margin of sternum IX \pm evenly concave, hind angles weakly dentate, posterior median area with dense and short greyish pubescence (Fig. 8c); lateral tergal sclerites IX with two terminal setae, shape as in Fig. 8d; ventral process with weak and short basal carina, parameres apically dilated; internal sac with 4 distinctly sclerotized structures: a small median basal, a larger median apical, and a pair of small oblong lateral pieces; flagellum thin and with ca. 25 coils (Figs 8a, b).

$:$ tergum $\mathrm{X}$ almost pointed posteriorly, its hind margin with numerous apically curved, long modified setae; styli slender, their inner margin with fringe of dense long setae (Fig. 8e).

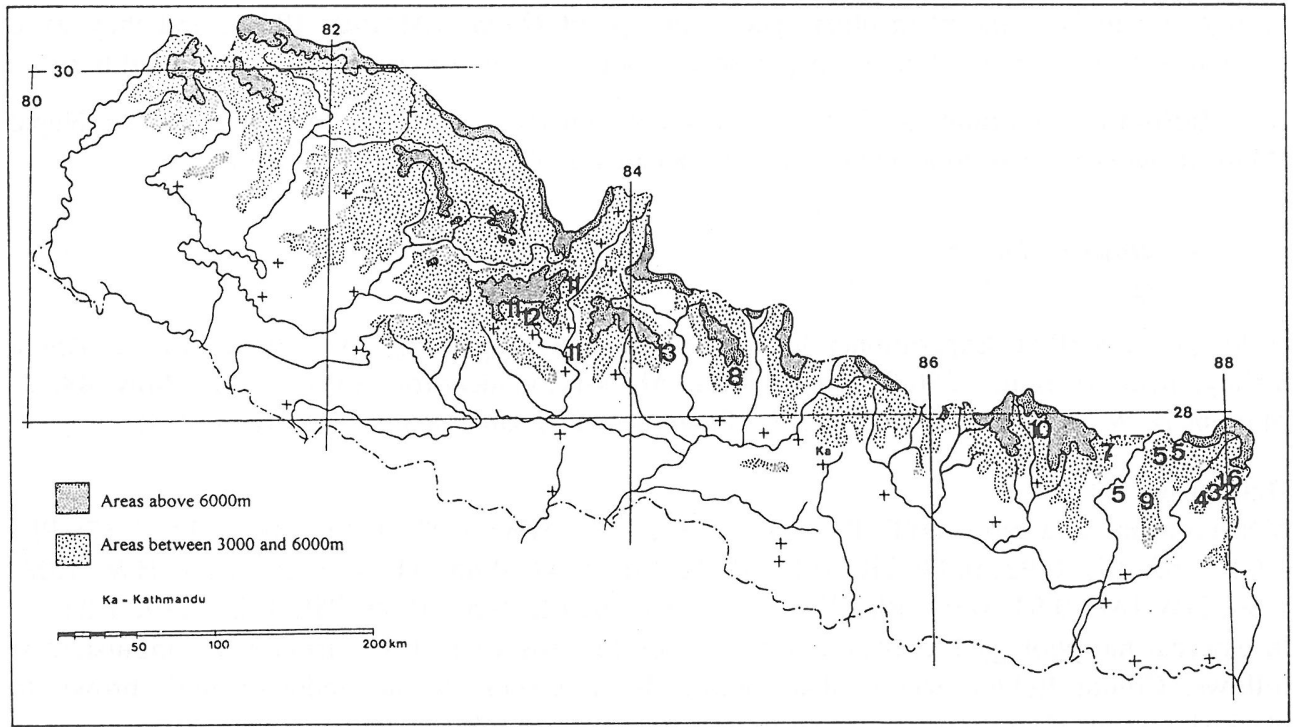

Map 2: Known distribution of the species of the $O$. infestus complex $(1-10)$ and of the $O$. kashmirica subgroup $(11-13)$ in Nepal: $O$. infestus $(\mathbb{1}), O$. acifer $(2), O$. conifer (3), O. truncatus (4), O. clavifer (5), O. corniger (6), O. virgifer (7), O. longicuneatus (8), O. perreaui (9), O. nepalensis (10), 0. deharvengi $(\mathbb{1 1})$, O. schawalleri (12), and $O$. jaegeri (13). Map by J. MARTENS, slightly modified.

Derivatio nominis: The name (lat.: hostile, menacing) refers to both the species' dark appearance and its long resistance to being identified as the third species within a complex of very closely related species from one and the same locality.

Comparative notes: From the closely related species below, O. infestus is distinguished particularly by its darker colour and by the $\delta$ primary and secondary sexual characters. 
Comments: Together with the following congeners, O. infestus belongs to a group of apparently extremely closely related species, most of which can only be identified based on the 0 primary and secondary sexual characters. All of them seem to have a very restricted area of distribution in the Himalayan mountain ranges of central and eastern Nepal. When first examining the material, which was mainly collected by J. Martens and W. Schawaller, my hypothesis was that, owing to the remarkable similarity not only in external appearance, but also in the general morphology of the aedeagus, the specimens studied represented only few highly variable species. This hypothesis, however, had to be rejected for several reasons. Even those specimens which clearly differed in the $\delta$ sexual characters were hardly separable based on external characters alone, a phenomenon also met with in other groups of Othius species (AssING, 1997). In addition, in the material from one locality three species could be clearly distinguished, which suggested that more species could be expected when specimens from further localities were examined. This assumption is also supported by the fact that most of the readily distinguished species were collected in only one locality, which hints at local endemism, and by morphological evidence, i. e. the reduction of the hind wings and the palisade fringe. Moreover, the differences observed, though sometimes rather inconspicuous, involved characters (sclerotized structures of the internal sac, length and width of flagellum; shape of $\delta$ sternum IX) which have been found to be constant in other species groups of Othius (AssING, 1997), and they were constant whenever more than one $\delta$ per species was available in the material examined here.

Distribution and bionomics: $O$. infestus is known only from the type locality in eastern Nepal (Map 2), where it was collected in the same locality as $O$. acifer and $O$. corniger.

\section{Othius acifer sp. $\mathrm{m}$.}

Figs 9 a - e, Map 2 (p. 313)

Holotype ơ: NEPAL-Expeditionen Jochen Martens/ 361 Taplejung Distr., upper Simbua Khola Valley, near Tseram, 3250-3350m, mature Abies-Rhododendron forest, 10-15 May 88, J. Martens \& W. Schawaller leg. (SMNS). Paratypes: 1 온, same data as holotype (cAss).

\section{Diagnosis}

Measurements and ratios (HT, PT): HL: 1.31, 1.37; HW: 1.22, 1.30; PW: 1.34, 1.37; PL: 1.62, 1.62; EL: 0.92, 0.98; TiL: 0.52, 0.56; TaL: 0.44, 0.45; TL: 8.9, 10.2; HL/HW: 1.08 , 1.06; HW/PW: 0.91, 0.94; PL/PW: 1.21, 1.18; EL/PL: 0.57, 0.55; TiL/TaL: 1.19, 1.23.

In external morphology highly similar to $O$. infestus, from which $O$. acifer is distinguished as follows. Colour lighter than in that species; head, pronotum and abdomen dark brown to blackish brown, elytra reddish brown to dark brown, appendages ferrugineous.

Anterior punctures of head in the two type specimens accompanied by $1(3 x)$ or $2(1 x)$ additional punctures.

Elytra with more even dorsal surface and somewhat smaller punctures.

¿: protarsi almost equally dilated in both sexes, sexual dimorphism hardly noticeable; sternum VIII with weakly convex hind margin; hind margin of sternum IX deeply and \pm evenly concave, hind angles weakly dentate, posterior median area with long and sparse, dark pubescence (Fig. 9c); lateral tergal sclerites IX as in Fig. 9d; aedeagus smaller than in $O$. infestus; ventral process with weak and short basal carina; internal sac with apical median piece relatively large and lateral structures short, thin and basally not distinctly dilated; flagellum thin and with only ca. 15 coils (Figs 9a, b).

$\%$ : tergum $X$ as in Fig. 9e. 

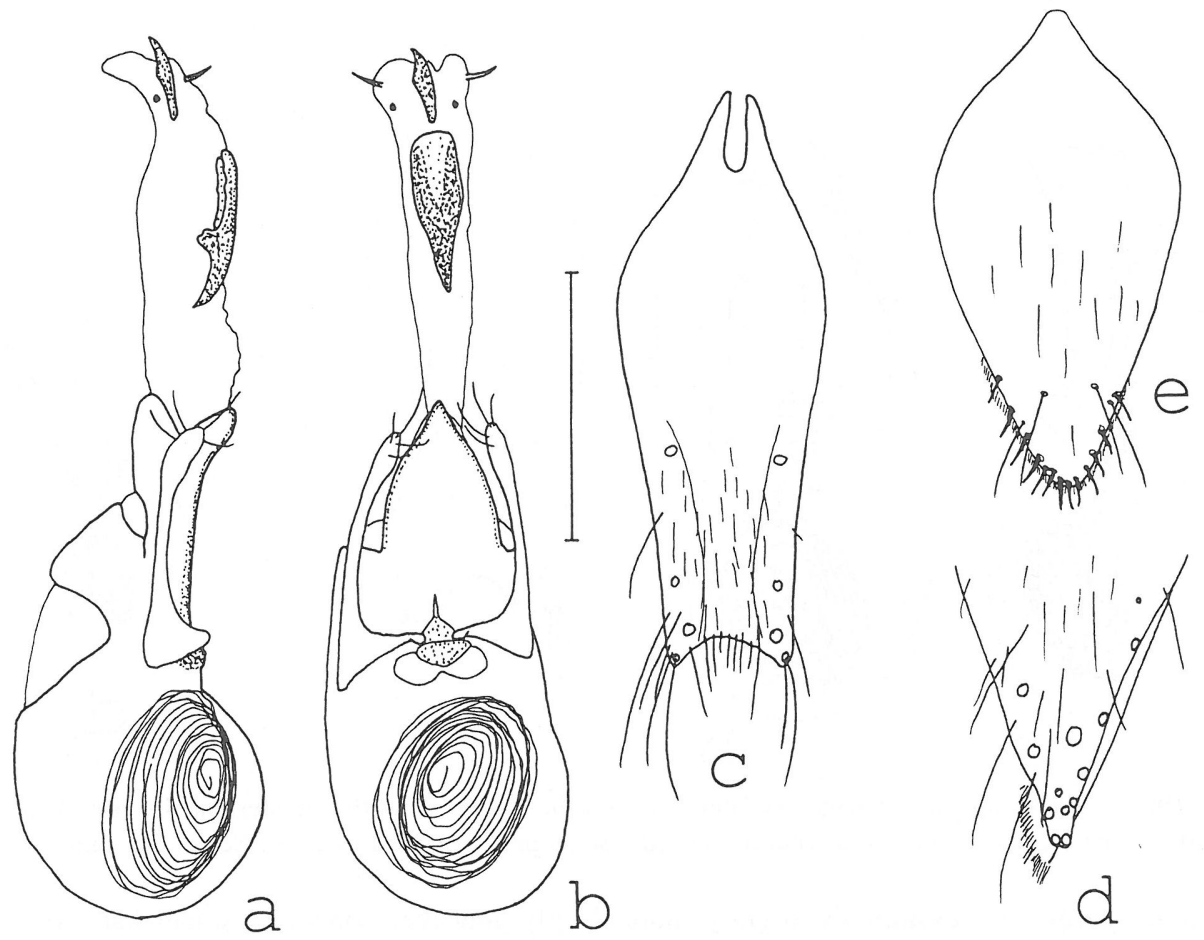

Fig. 9: O. acifer sp. n.: aedeagus in lateral (a) and in ventral view (b); $\delta$ sternum IX (c); posterior part

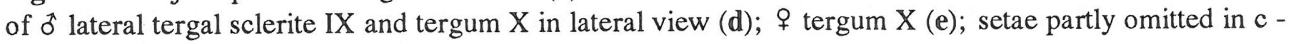
e. Scale: $0.5 \mathrm{~mm}$.

Derivatio nominis: The name (acus (lat.): needle) refers to the shape of the pair of lateral structures in the internal sac, a character distinguishing $O$. acifer from the related species.

Comparative notes: For separation from $O$. festivus see diagnosis; for distinction from the remaining species of the complex see below.

Distribution and bionomics: The species is known only from one locality in eastern Nepal (Map 2), where it was collected together with $O$. infestus and $O$. corniger.

Othius conifer sp. n.

Figs $10 \mathrm{a}-\mathrm{d}$

Holotype o: NEPAL-Expeditionen Jochen Martens/ 367 Taplejung Distr., pass Deorali W Yamputhin, 3400m, Abies Rhododendron forest, 17 May 88, J. Martens \& W. Schawaller leg. (SMNS). Paratype $q$ : same data as holotype (cAss).

\section{Diagnosis}

Measurements and ratios (HT, PT): HL: 1.31, 1.43; HW: 1.28, 1.40; PW: 1.37, 1.46; PL: 1.65, 1.74; EL: 0.88, 0.98; TiL: 0.56, 0.59; TaL: 0.44, 0.47; TL: 8.9, 10.7; HL/HW: 1.02, 1.02; HW/PW: 0.93, 0.96; PL/PW: 1.20, 1.19; EL/PL: 0.54, 0.56; TiL/TaL: 1.28, 1.26.

Colour, except for the darker, pitchy brown legs and blackish brown elytra, and external morphology as in $O$. acifer, from which this species is distinguished as follows.

Anterior punctures of head in the holotype accompanied by 1 additional puncture. 

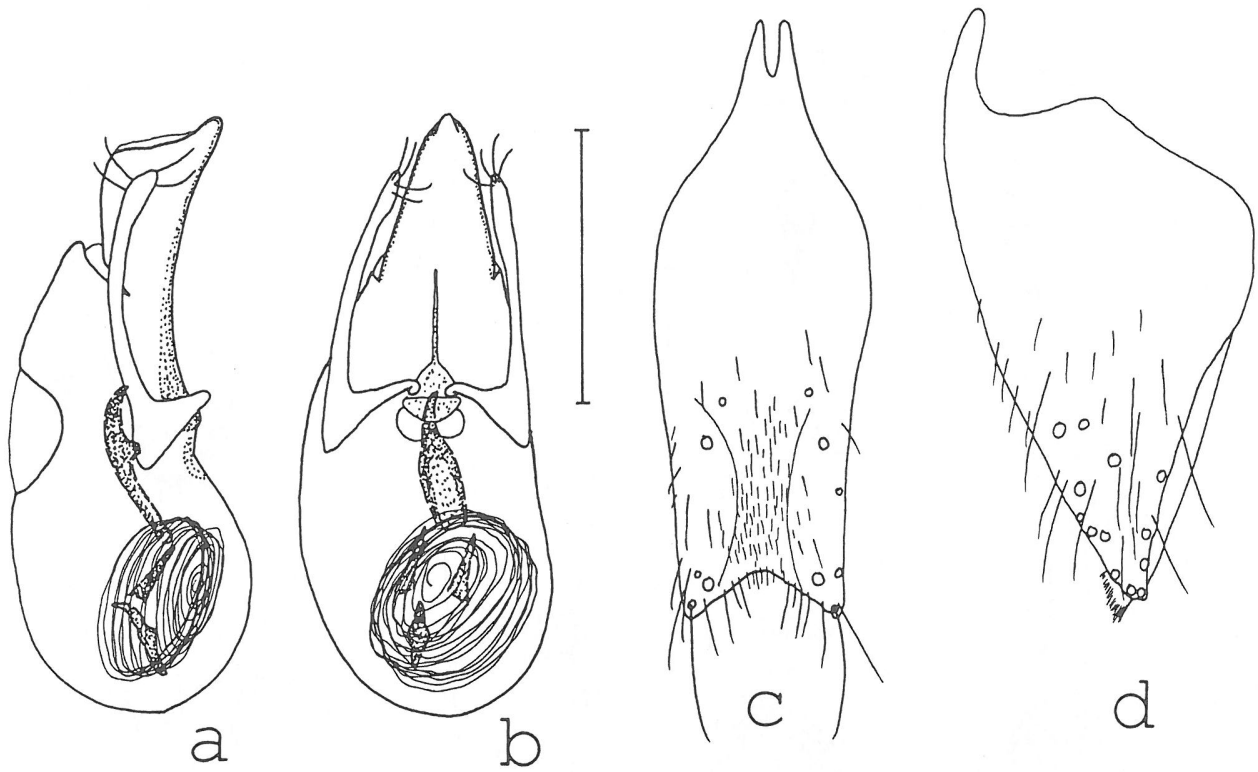

Fig. 10: O. conifer sp. n.: aedeagus in lateral (a) and in ventral view (b); $\delta$ sternum IX (c); $\delta$ lateral tergal sclerite IX and tergum $X$ in lateral view (d); setae partly omitted in $\mathrm{c}-\mathrm{d}$. Scale: $0.5 \mathrm{~mm}$.

$\delta$ : hind margin of sternum IX slightly more deeply concave, concavity somewhat more Vshaped, posterior median area with dense and short yellowish pubescence (Fig. 10c); lateral tergal sclerite IX as in Fig. 10d; aedeagus larger, ventral process with longer and more distinct basal carina; internal sac with apical median piece slightly smaller, basal median piece apically more strongly curved and lateral pieces distinctly larger and coniform; flagellum thinner and with more, ca. 20-25 coils (Figs 10a, b).

$:$ t tergum $\mathrm{X}$ as in $O$. clavifer (cf. Fig. 12f).

Derivatio nominis: The name refers to the coniform shape of the pair of sclerotized lateral structures in the internal sac, a character distinguishing this species from its closely related congeners.

Comparative notes: From $O$. infestus, $O$. conifer is distinguished by the lighter colour, the more even surface and smaller punctures of the elytra, the more deeply concave and differently pubescent $\delta$ sternum IX and the different shape of the sclerotized structures in the internal sac. For distinction from $O$. acifer see diagnosis. From all the following congeners, $O$. conifer is separated by the deeply concave hind margin of the $\delta$ sternum IX and further $\delta$ sexual characters.

Distribution and bionomics: The species is known only from the type locality in eastern Nepal, where it was collected under similar ecological circumstances (altitude, vegetation) as its closely related congeners.

Othius truncatus sp. $\mathrm{n}$.

Figs 11 a - c, Map 2 (p. 313)

Holotype $\delta:$ NEPAL-Expeditionen Jochen Martens/ 359 Taplejung Distr., pasture Lassetham NW Yamputhin, 3300-3500m, mature Abies-Rhododendron forest, 6-9 May 1988, J. Martens \& W. Schawaller leg. (SMNS). 


\section{Diagnosis}

Measurements and ratios (HT): HL: 1.31; HW: 1.19; PW: 1.31; PL: 1.56; EL: 0.84; TiL: 0.51; TaL: 0.44; TL: 9.5; HL/HW: 1.10; HW/PW: 0.91; PL/PW: 1.19; EL/PL: 0.54; TiL/TaL: 1.17 .

Colour and external morphology as in $O$. acifer and, apart from the slightly lighter colour also highly similar to $O$. conifer, but head more slender and tarsi relatively shorter (cf. ratios). Anterior punctures of head in the holotype accompanied by 2 additional punctures.
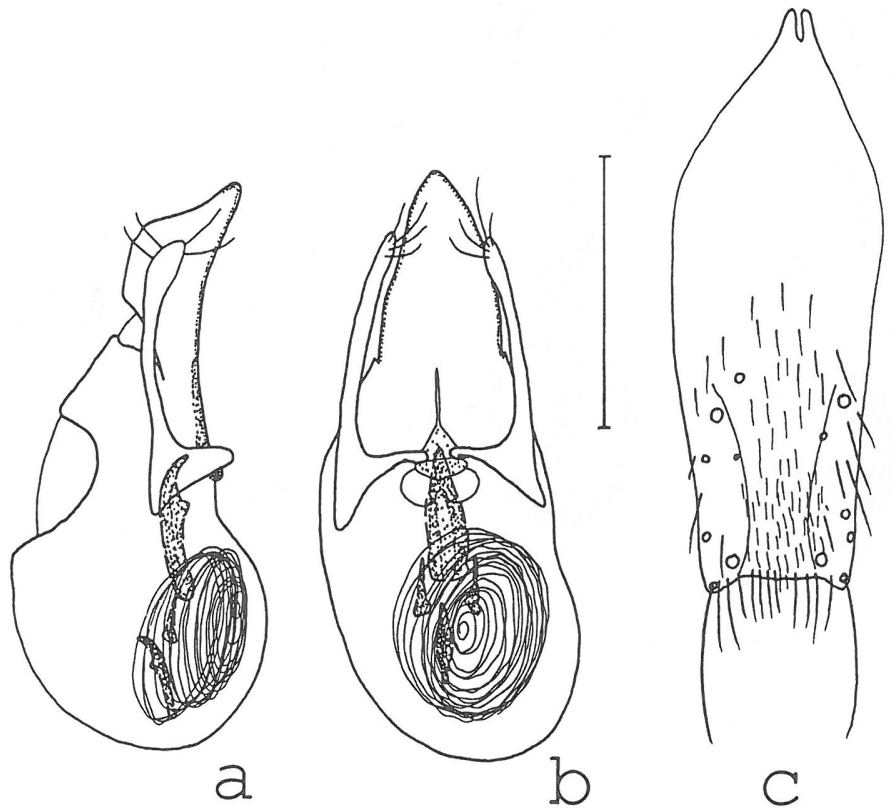

Fig. 11: O. truncatus sp. n.: aedeagus in lateral (a) and in ventral view (b); $\delta$ sternum IX (c); setae partly omitted in c. Scale: $0.5 \mathrm{~mm}$.

$\delta:$ hind margin of sternum IX centrally truncate, pubescence of posterior median area as in $O$. conifer (Fig. 11c); aedeagus of similar size and shape as in $O$. conifer, but ventral process with slightly shorter basal carina, and the internal sac with the basal median piece and the pair of lateral pieces of different shape; flagellum thin and with ca. 20-25 coils (Figs 11a, b).

ㅇ: unknown.

Derivatio nominis: The name refers to the truncate hind margin of the $\delta$ sternum IX, which distinguishes this from the preceding species of the $O$. infestus complex.

Comparative notes: From $O$. infestus, $O$. conifer, and $O$. acifer, this species is distinguished by the different shape of the $\delta$ sternum IX and of the sclerotized structures of the internal sac, from $O$. infestus and $O$. conifer in addition by the lighter colour especially of the legs, from $O$. infestus and $O$. acifer by the different pubescence of the $\delta$ sternum IX, from $O$. acifer by the larger aedeagus and the longer flagellum.

Distribution and bionomics: The species is known only from the type locality in eastern Nepal (Map 2), where it was collected under similar ecological circumstances as its closely related congeners. 

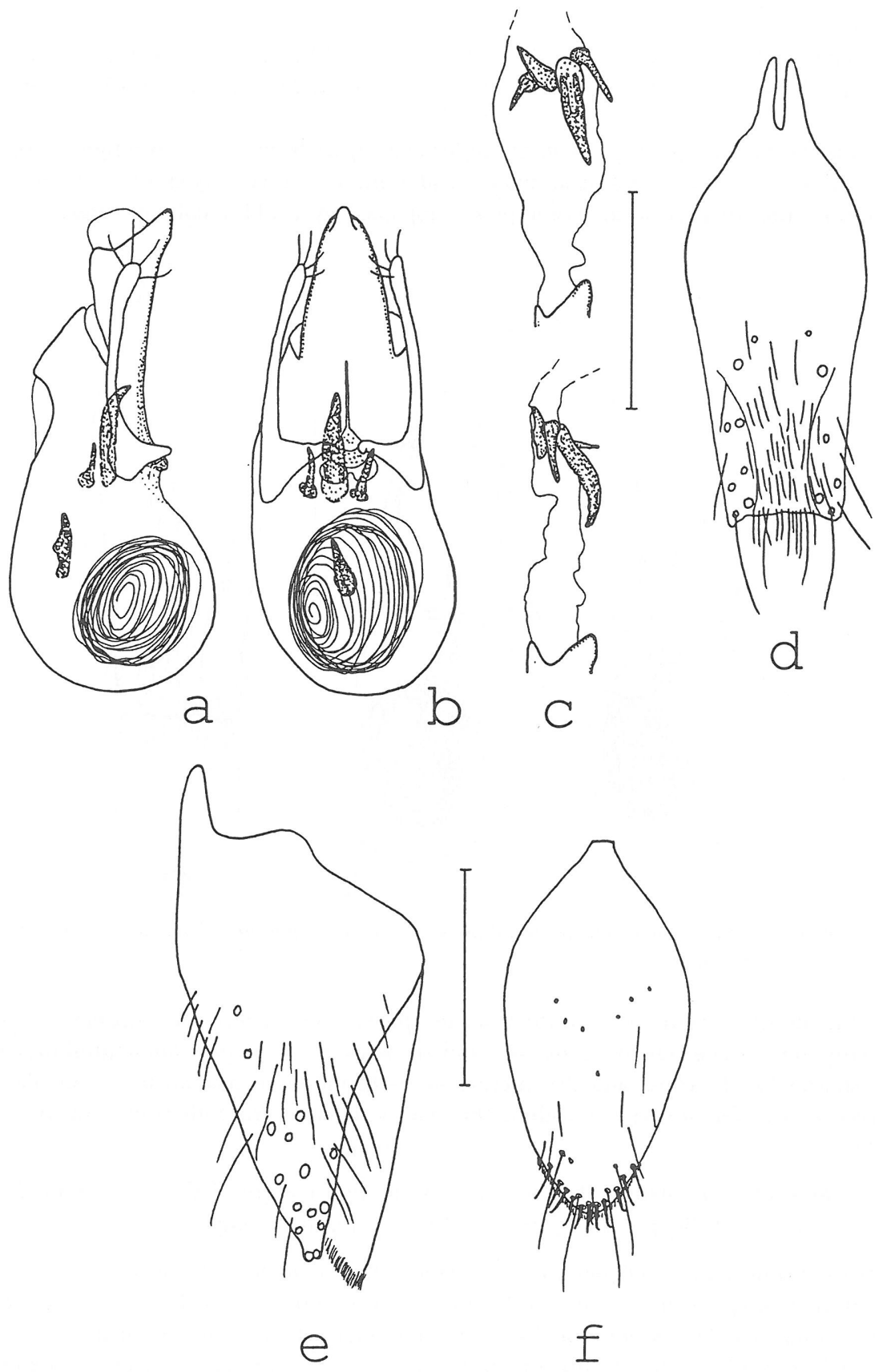

Fig. 12: $O$. clavifer sp. n.: aedeagus in lateral (a) and in ventral view (b); internal sac and internal structures of further $\delta$ in two different aspects (c); $\delta$ sternum IX (d); $\delta$ lateral tergal sclerite IX and tergum $\mathrm{X}$ in lateral view (e); $\uparrow$ tergum $\mathrm{X}(\mathrm{f})$; setae partly omitted in $\mathrm{d}$ - e. Scales: $0.5 \mathrm{~mm}$. 
Othius clavifer sp. m.

Figs 12 a - f, Map 2 (p. 313)

Holotype đ: NEPAL-Expeditionen Jochen Martens/ 390 Sankhua Sabha Distr., Thudam, mixed forest mainly Betula/Rhododendron, 3550-3650m, 25-27 May 88, J. Martens \& W. Schawaller (SMNS). Paratypes: 10, 1 , NEPAL-Expeditionen Jochen Martens/ 387 Sankhua Sabha Distr., Kangla Khola E Thudam, dwarf Rhododendron, rock debris, 4100-4200m, 24-25 May 88, J. Martens \& W. Schawaller leg. (SMNS, cAss); 1 온 Sankhua Sabha Distr., Arun Valley, Chichila, 1900-2000m, Quercus forest, bushes near village, 18-20 June 88, J. Martens \& W. Schawaller (SMNS).

\section{Diagnosis}

Measurements and ratios (range; $\mathrm{n}=4$ ): HL: 1.36 - 1.46; HW: $1.22-1.31$; PW: $1.28-1.40$; PL: 1.59 - 1.71; EL: $0.89-1.01$; TiL: 0.56- 0.60; TaL: $0.45-0.50$; TL: $9.0-10.8$; HL/HW: 1.09 - 1.12; HW/PW: 0.94 - 0.96; PL/PW: 1.21 - 1.24; EL/PL: 0.55 - 0.59; TiL/TaL: 1.19 1.27 .

In external morphology highly similar to $O$. acifer, from which it is distinguished as follows. Colour of elytra on average even lighter, ferrugineous, more strongly contrasting with the remainder of the forebody and the abdomen.

Anterior punctures of head accompanied by $1-2$ additional punctures.

Elytra with somewhat more shine due to distinctly weaker microsculpture, which is predominantly composed of fine and rather dense micropunctation rather than microreticulation; punctures larger and more distinct, and dorsal surface more uneven than in $O$. acifer; posterior margin slightly bent downwards especially near posterior angles, posterior region therefore appearing somewhat convex.

$\delta$ : sternum VIII with convex hind margin; hind margin of sternum IX truncate, with weakly dentate hind angles, posterior median area with long and rather dense, dark pubescence (Fig. $12 \mathrm{~d}$ ); lateral tergal sclerite as in Fig. 12e; aedeagus of similar size as in $O$. conifer; ventral process with weak basal carina; internal sac with apical median piece without distinct ventral tooth, basal piece in ventral view relatively broad and in lateral view with distinct median dilatation, and the pair of lateral pieces shaped like nails; flagellum thin and with ca. 20 coils (Figs 12 a - c).

\%: tergum $\mathrm{X}$ as in Fig. $12 \mathrm{f}$.

Derivatio nominis: The name (clavus (lat.): nail) refers to the characteristic shape of the pair of lateral structures in the internal sac.

Comparative notes: From all the related species, $O$. clavifer is externally distinguished by the microsculpture of the elytra and by the shape of the internal structures of the aedeagus, from $O$. infestus, $O$. acifer and $O$. conifer in addition by the shape of the hind margin of the $\delta$ sternum IX.

Comments: There were two further $q q$ in the collections of the SMNS with the same data as the holotype. However, as they differ from the type specimens indicated above not only in the distinctly darker colour, but also in the somewhat more distinct microreticulation of the elytra, they were not included in the type series.

Distribution and bionomics: The species is known from three localities in the Sankhua Sabha District in eastern Nepal (Map 2), where it was collected under much the same ecological circumstances as the other species of the $O$. infestus species complex. 
Othius virgifer sp. n.

Figs 13 a - d, Map 2 (p. 313)

Holotype ơ: O. Nepal, 1980, W. Wittmer/ Numbug [=Mumbug], O Makalu, 3500-3700m, 11.6. (NHMB). Paratype $\uparrow$, same data as holotype (cAss).

\section{Diagnosis}

Measurements and ratios (HT, PT): HL: 1.49, 1.53; HW: 1.37, 1.39; PW: 1.46, 1.46; PL: 1.74, 1.74; EL: 0.95, 1.04; TiL: 0.65, 0.63; TaL: 0.50, 0.50; TL: 9.7, 11.5; HL/HW: 1.09, 1.10; HW/PW: 0.94, 0.95; PL/PW: 1.19, 1.19; EL/PL: 0.54, 0.60; TiL/TaL: 1.30, 1.27. In external morphology highly similar to $O$. acifer, but larger (see measurements). Anterior punctures of head accompanied by 2 additional punctures.
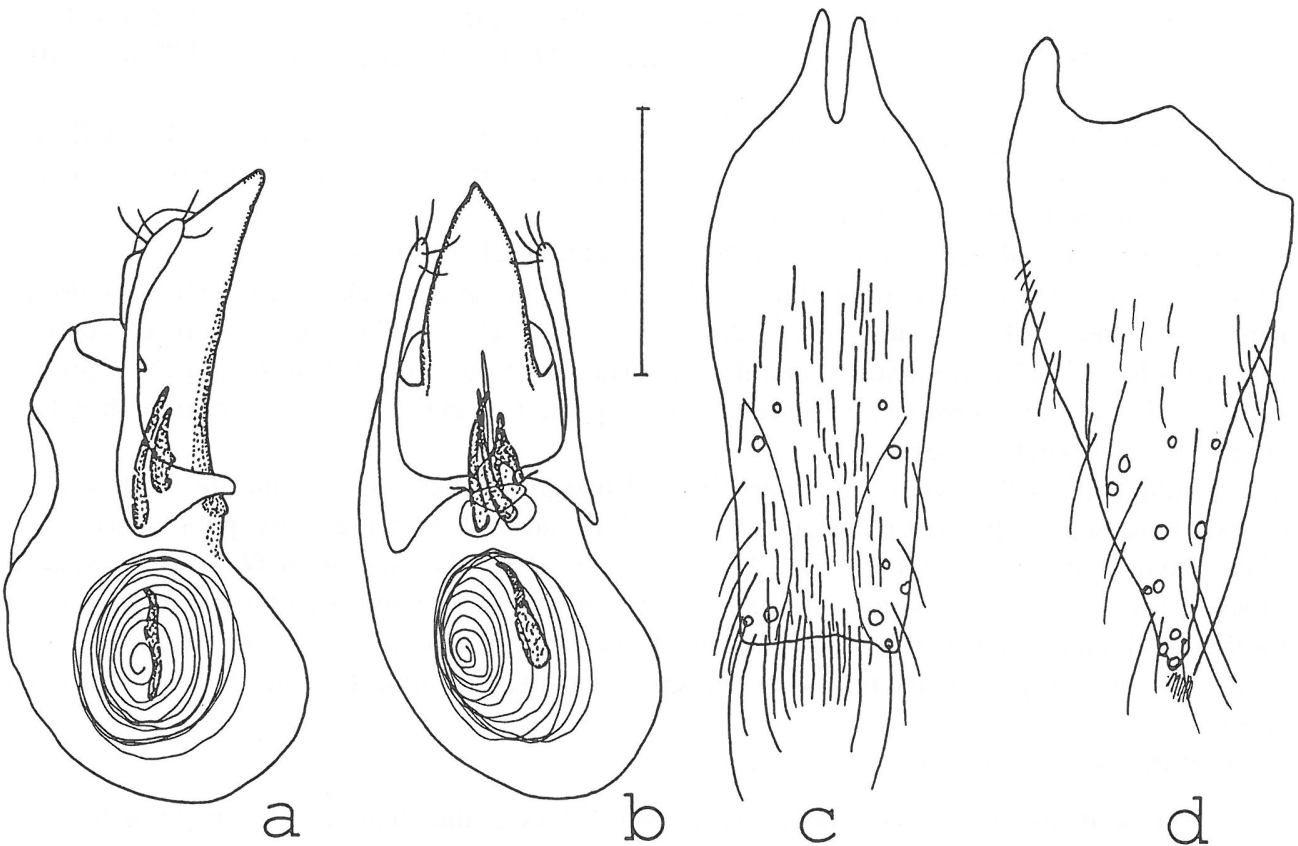

Fig. 13: $O$. virgifer sp. n.: aedeagus in lateral (a) and in ventral view (b); $\delta$ sternum IX (c); $\delta$ lateral tergal sclerite IX and tergum X in lateral view (d); setae partly omitted in c - d. Scale: $0.5 \mathrm{~mm}$.

ठ: sternum VII weakly concave posteriorly; sternum VIII with slightly concave hind margin; hind margin of sternum IX very weakly concave, hind angles not distinctly dentate, posterior median area with rather long and not very dense, dark pubescence (Fig. 13c); lateral tergal sclerite IX as in Fig. 13d; aedeagus of similar size as in $O$. conifer; ventral process with rather long basal carina; internal sac with apical median piece small, shorter even than the elongate basal piece, and the pair of lateral pieces very long; flagellum relatively wide and with only ca. 10-12 coils (Figs 13a, b).

\%: tergum $\mathrm{X}$ similar to the related species.

Derivatio nominis: The name (virga (lat.): stick, rod) refers to the characteristic shape of the pair of lateral structures in the internal sac. 
Comparative notes: From all the related species, 0 . virgifer is distinguished by its larger size, especially the longer head, and the characteristic shape of the structures (sclerotized pieces, flagellum) in the internal sac.

Distribution and bionomics: Like the preceding species of the $O$. infestus complex, $O$. virgifer is apparently a local endemic in eastern Nepal (Map 2), where it was also collected at a similar altitude.

\section{Othius corniger sp. n.}

Figs $14 \mathrm{a}-\mathrm{g}$, Map 2 (p. 313)

Holotype 0 : NEPAL-Expeditionen Jochen Martens/ 361 Taplejung Distr., upper Simbua Khola Valley, near Tseram, 3250-3350m, mature Abies-Rhododendron forest, 10-15 May 88, J. Martens \& W. Schawaller leg. (SMNS). Paratypes: 10 , 19 , same data as holotype (SMNS, cAss).

\section{Diagnosis}

Measurements and ratios (HT, ठPT, ९PT): HL: 1.37, 1.43, 1.53; HW: 1.25, 1.25, 1.30; PW: $1.40,1.43,1.53$; PL: $1.59,1.69,1.75$; EL: 0.87, 0.95, 1.04; TiL: 0.57, 0.56, 0.62; TaL: $0.48,0.50,0.54$; TL: 9.5, 9.5, 11.2; HL/HW: 1.10, 1.15, 1.09; HW/PW: 0.89, 0.87, 0.92; PL/PW: 1.13, 1.18, 1.15; EL/PL: 0.55, 0.56, 0.59; TiL/TaL: 1.18, 1.12, 1.14.

In external morphology most similar to $O$. infestus. Whole body including appendages \pm uniformly blackish.

Head with less shine than in the other species of the $O$. infestus complex; with characteristic microsculpture, distinctly microreticulate with interspersed micropunctation; anterior punctures of head accompanied usually by 3 additional punctures.

Pronotum with the posterior discal puncture clearly distant from the hind angles (Fig. 14f); microsculpture distinct and predominantly composed of isodiametric or transverse meshes of variable length; dorsal surface rather mat.

Elytra with somewhat uneven dorsal surface; punctures more evenly spaced than in $O$. infestus and smaller, partly weakly granulose.

$\delta$ : sternum VII and VIII weakly concave posteriorly; hind margin of sternum IX very weakly concave with dentate hind angles, posterior median area with weakly darkened pubescence of intermediate length and density (Fig. 14d); lateral tergal sclerite IX as in Fig. 14e; ventral process of characteristic shape both in ventral and in lateral view; internal sac with very characteristic internal structures: one median piece, a pair of short needle-like pieces and a pair of conspicuous structures somewhat resembling the antlers of a deer; flagellum thin and with ca. 20-25 coils (Figs 14 a - c).

\%: tergum X oblong and pointed, its hind margin without distinctly modified setae (Fig. 14g).

Derivatio nominis: The name (with horns or antlers) refers to the shape of the larger pair of lateral structures in the internal sac.

Comparative notes: From all the species of the $O$. infestus complex, $O$. corniger is readily distinguished by the microsculpture of the head, the pronotal punctation pattern, and the shape and internal structures of the aedeagus.

Distribution and bionomics: $O$. corniger is known only from the type locality in eastern Nepal (Map 2), where it was collected together with $O$. infestus and $O$. acifer. 


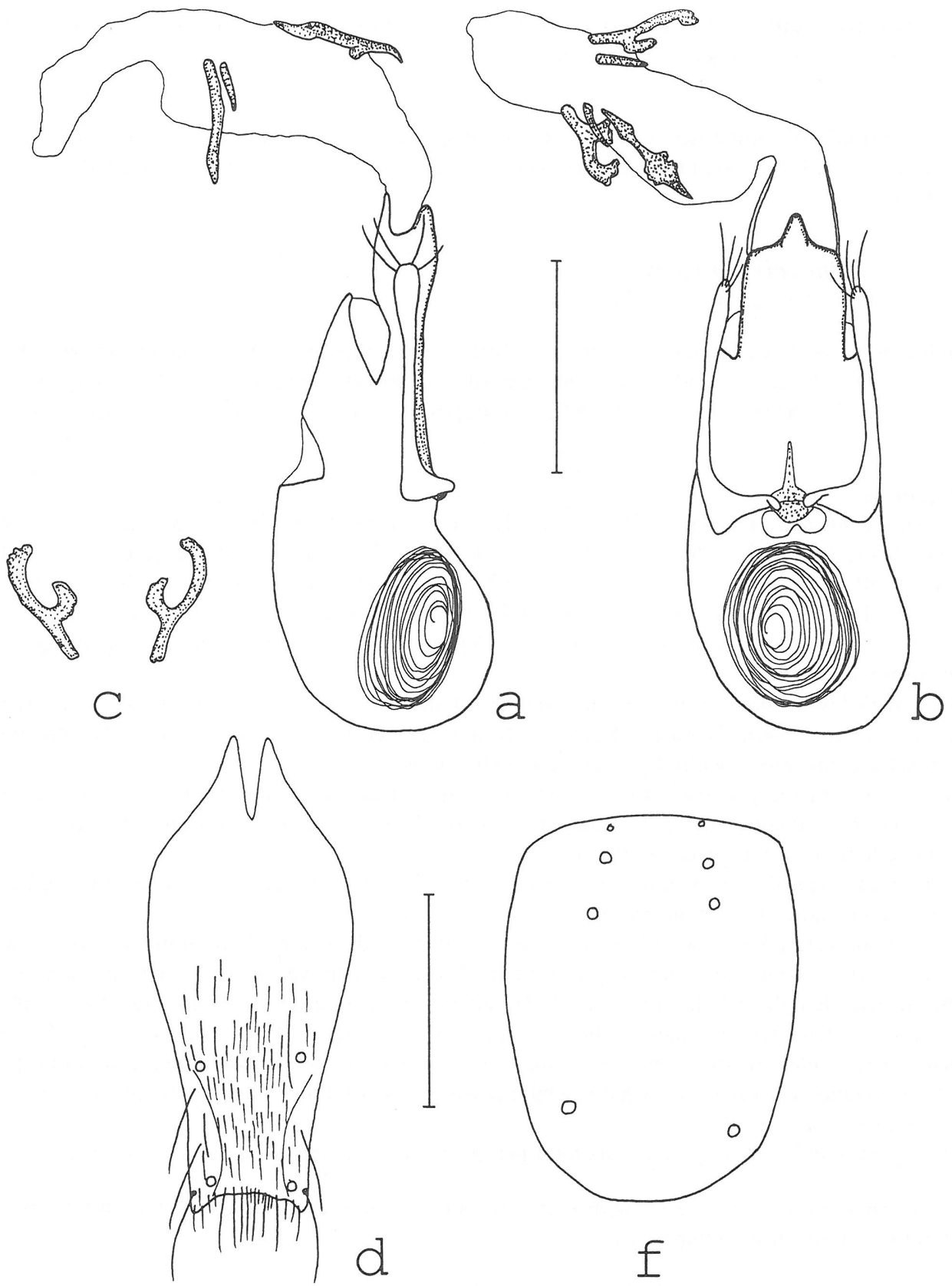

Fig. 14: $O$. corniger sp. n.: aedeagus in lateral (a) and in ventral view (b); antler-shaped lateral internal structures in different aspect (c); $\delta$ sternum IX (d); $\hat{\sigma}$ lateral tergal sclerite IX and tergum X in lateral view (e); schematic representation of variability (left - right) of position of pronotal punctures (f); $q$ terminalia (g); setae partly omitted in d, e, g. Scales: $0.5 \mathrm{~mm}$ (f without scale). 

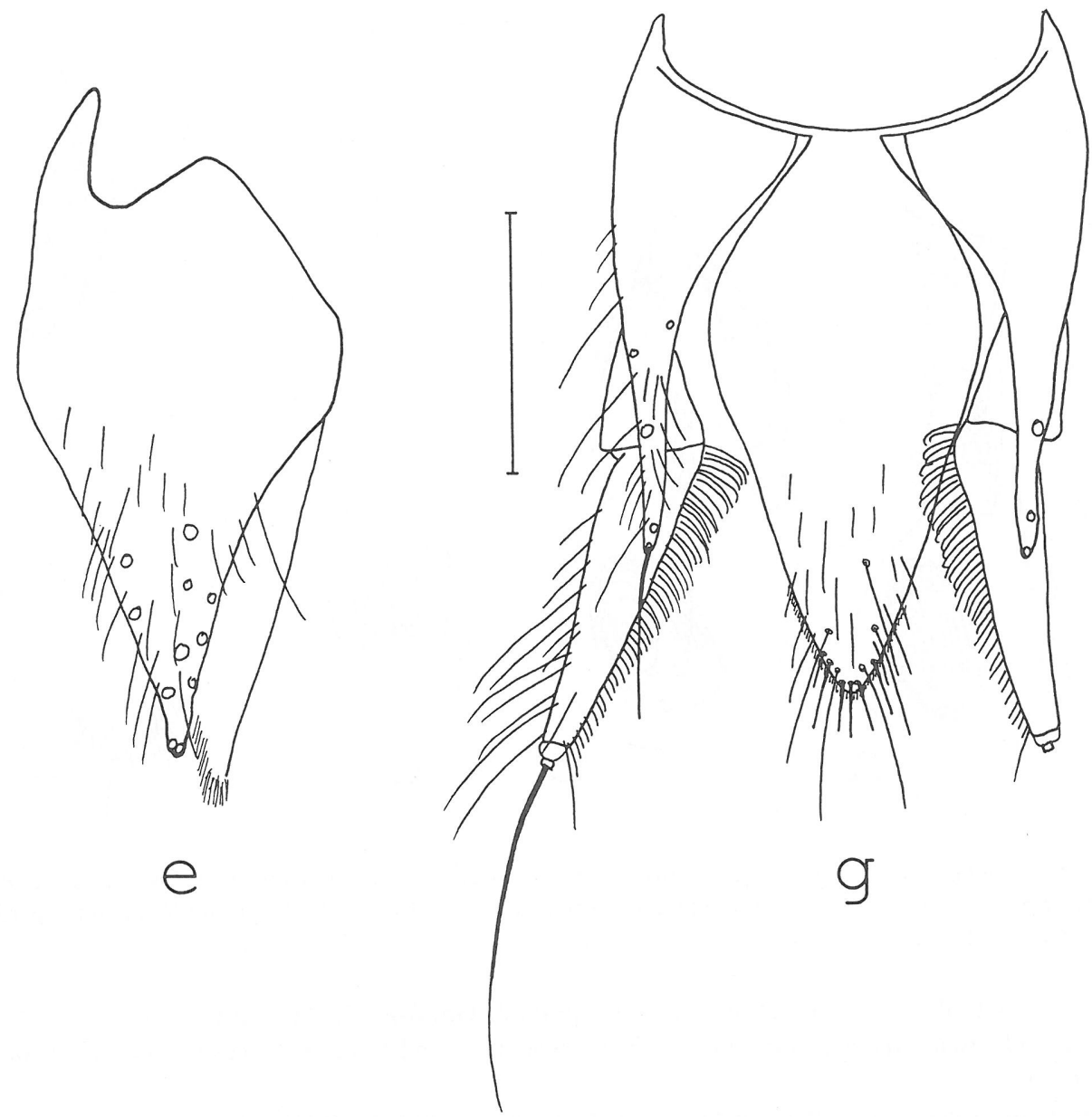

Othius longicuneatus $\mathrm{sp} . \mathrm{n}$.

Figs 15 a - e, Map 2 (p. 313)

Holotype $\delta: 242$ Gorkha Dist., Darondi Khola bis oberhalb Barpak, 3600-3450m, Wald, 10 Aug. 83, Martens \& Schawaller leg. (SMNS).

Paratype + [distinctly teneral]: same data as holotype (cAss).

\section{Diagnosis}

Measurements and ratios (HT, PT): HL: 1.27, 1.31; HW: 1.14, 1.19; PW: 1.24, 1.25; PL: 1.46, 1.43; EL: 0.8, 1.85; TiL: 0.53, 0.53; TaL: 0.42, 0.41; TL: 8.7, 9.0; HL/HW: 1.11, 1.10; HW/PW: 0.93, 0.95; PL/PW: 1.19, 1.15; EL/PL: 0.58, 0.60; TiL/TaL: $1.25,1.30$.

In external morphology similar to $O$. infestus and related species, but somewhat smaller and body colour distinctly lighter, \pm uniformly reddish brown, with the tarsi, parts of the tibiae and femora, and the antennal flagellum yellowish brown.

Head with microsculpture composed of transverse striae and transverse meshes; anterior punctures of head accompanied 1 - 2 additional punctures. 

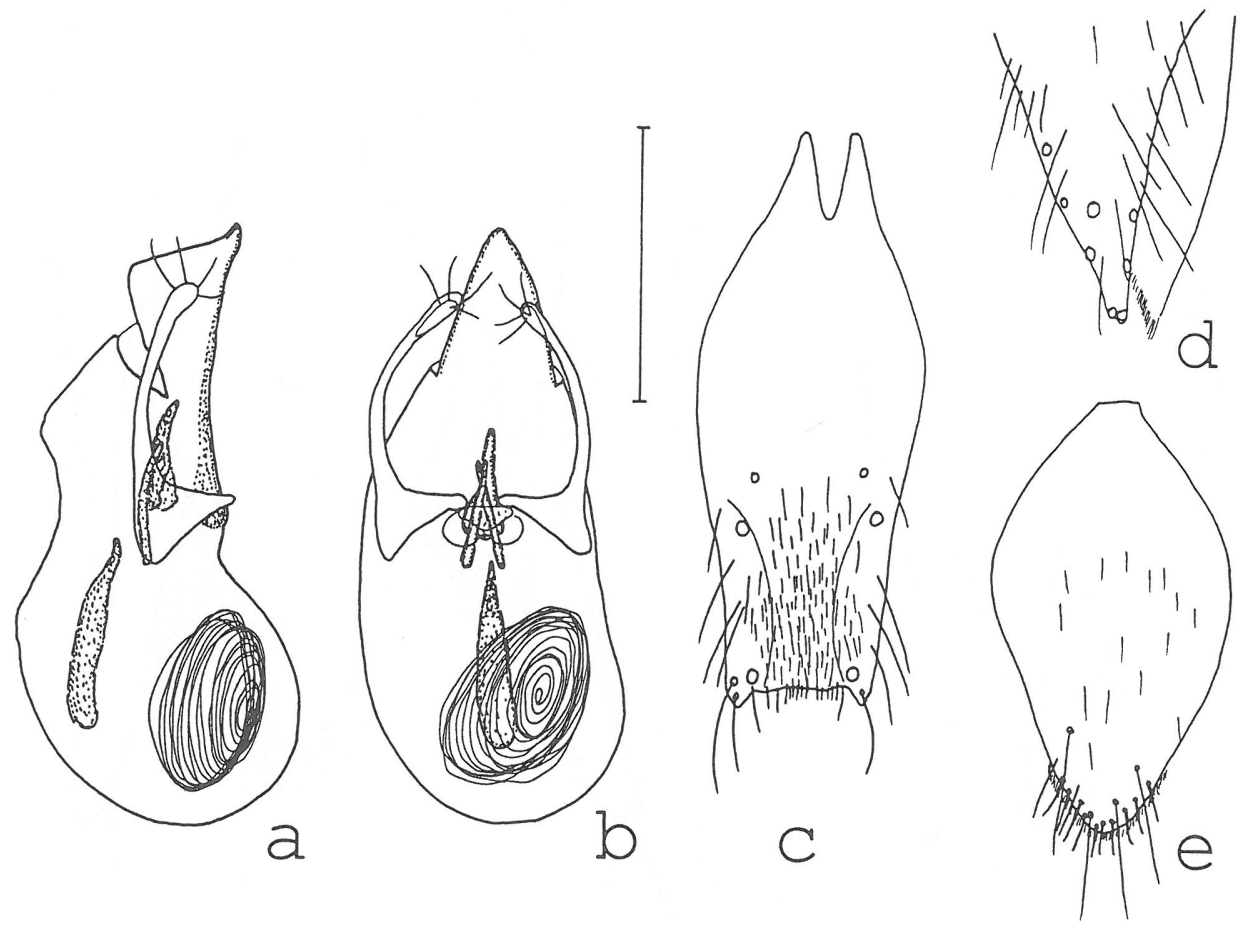

Fig. 15: O. longicuneatus sp. $\mathrm{n} .:$ aedeagus in lateral (a) and in ventral view (b); $\hat{o}$ sternum IX (c); posterior part of $\delta$ lateral tergal sclerite IX and tergum $X$ in lateral view (d); $q$ tergum $X(e)$; setae partly omitted in c - d. Scale: $0.5 \mathrm{~mm}$.

Pronotum with the posterior discal puncture slightly distant from the hind angles; microsculpture distinct and predominantly composed of transverse striae and transverse meshes; dorsal surface rather mat.

Elytra with rather even dorsal surface; punctures sparse and irregularly spaced, posterior part of suture gaping; hind wings reduced.

Abdomen with fine and rather sparse punctation; microsculpture near anterior margins of terga composed of isodiametric or short transverse meshes, on remainder of tergal surfaces transverse and very shallow.

$\delta$ : sternum VII truncate, sternum VIII weakly convex posteriorly; hind margin of sternum IX \pm truncate with dentate hind angles, posterior median area with dense, short and light-coloured pubescence (Fig. 15c); lateral tergal sclerite as in Fig. 15d; ventral process of median lobe without distinct basal carinae; internal sac with characteristic internal structures: a very long median basal, a shorter median apical, and a pair of oblong lateral pieces; flagellum thin and with ca. 20-25 coils (Figs 15a, b).

: tergum $\mathrm{X}$ acutely convex, posteriorly with weakly modified, not very stout and apically weakly bent setae (Fig. 15e).

Derivatio mominis: The name (lat.) refers to the long wedge-shaped basal median structure in the internal sac, one of the most prominent characters distinguishing this species from its closely related congeners. 
Comparative notes: Among the species of the $O$. infestus complex, O. longicuneatus shares its brownish colour only with $O$. nepalensis (Scheerpeltz), whose $\delta$ sexual characters are unknown (see below). In addition, it is readily distinguished by the internal structures of the aedeagus, particularly the long basal median piece.

Distribution and bionomics: As far as is currently known, this central Nepalese species is the westernmost representative of the $O$. infestus species complex (Map 2). The reduction of the wings and palisade fringe as well as the altitude of the type locality and the distibution of the related species suggest that $O$. longicuneatus is more or less endemic, so that in spite of external similarities with $O$. nepalensis (Scheerpeltz), which is known only from the Mt. Everest region, it is here considered to represent a distinct species.

Othius perreaui COIFFAIT, 1984

Map 2 (p. 313)

Othius perreaui COIFFAIT, 1984: 376

Type examined

Holotype $9:$ Nepal or. 7.83, Milke Himal, 2000m/ Type/ Muséum Paris 1985, coll. H. Coiffait/ Othius perreaui H. Coiffait (MNHNP).

\section{Diagnosis}

Measurements and ratios (HT): HL: 1.40; HW: 1.31; PW: 1.43; PL: 1.71; EL: 0.92; TiL: 0.59; TaL: 0.48; TL: 10.5; HL/HW: 1.07; HW/PW: 0.92; PL/PW: 1.19; EL/PL: 0.54; TiL/TaL: 1.22 .

Externally extremely similar to $O$. virgifer, from which this species is distinguished by the shorter, the more distinctly microreticulate and therefore matter elytra.

o: unknown.

\%: terminalia as in the related species of the $O$. infestus complex.

Comments: $O$. perreaui doubtlessly belongs to the $O$. infestus species complex, in which $\delta \delta$ are essential for identification. However, since the original description is based on a single female, the identity of this species cannot be adequately diagnosed until males from the type locality (Map 2) become available. As practically all the closely related congeners appear to be local endemics, $O$. perreaui is unlikely to be conspecific with any of the species described above.

Othius nepalensis (SCHEERPELTZ, 1976), comb. n. Map 2 (p. 313)

Othiogeiton nepalensis SCHEERPELTZ, 1976a: 32ff

Type: Holotype 9 [somewhat damaged apparently in the course of examination by the author of the species; forelegs glued in the place of middle legs and vice versa]: + Himalaya-Expedition Prof. Dr. H. JANETSCHEK 1961 nach Nepal/ No-61/308/ Othiogeiton n. gen. nepalensis n. sp./ Allotypus [sic!]/ Typus Othiogeiton nepalensis O. Scheerpeltz/ Othiogeiton n. gen. nepalensis n. sp. det Scheerpeltz (IZI).

\section{Description of holotype}

Measurements and ratios (HT): HL: 1.16; HW: 1.07; PW: 1.16; PL: deformed, not measured; EL: 0.76; TiL: 0.48; TaL: 0.39; TL: specimen deformed, not measured; HL/HW: 1.09;

HW/PW: 0.92; TiL/TaL: 1.23. 
General morphology, apart from the slightly smaller size (see measurements), as in the other species of the $O$. infestus complex, where this species belongs; in size and colour most similar to $O$. longicuneatus. Colour \pm brown with the elytra somewhat lighter and the appendages ferrugineous.

Head with large, \pm triangular impression on frons (artefact?), in which the anterior frontal punctures are situated; additional punctures absent; microsculpture predominantly transverse.

Pronotum, especially anterior part, somewhat damaged and partly missing; in posterior half with large median impression, which may well be a deformation; microsculpture distinct and transverse.

Elytra with sparse, irregularly spaced and shallow punctation; microsculpture distinct, composed partly of isodiametric meshes and partly of dense micropunctation.

Abdomen with fine, but rather distinct transverse microsculpture.

: protarsi and terminalia as in the related congeners.

Comments: The original description indicates only a single "Allotypus", which, in the absence of a second specimen, must be regarded as the holotype. The genus Othiogeiton, described by SCHEERPELTZ (1976a) in the same paper, includes only O. nepalensis, the type species by explicit designation. According to SCHEERPELTZ (1976a) the new genus is distinguished from other Othiini "außer durch die Mundteile [without further specifications], sofort durch die andere Skulptur der Oberflächen von Kopf und Halsschild". None of the characters indicated is justified, partly because they are based on artefacts, malformations or misinterpretation (especially the punctation and shape of the probably malformed pronotum). Since $O$. nepalensis is a typical Othius most closely related to the species of the $O$. infestus complex, Othiogeiton SCHEERPELTZ is here synonymized with Othius STEPHENS. As is the case with $O$. perreaui, the identity of $O$. nepalensis, too, is insufficiently and inadequately characterized until $\delta \delta$ from the type locality are available for study.

Distribution: The species has become known only from the type locality in the Mt. Everest region (Map 2): "Unterhalb Almsiedlung Taboche, ca. $4500 \mathrm{~m}$, Formolfalle; 12. bis 31. Mai 1961" (SCHEERPELTZ 1976a).

\section{Othius kashmirica CAMERON, 1943}

Figs 16 a - $f$

Othius kashmirica CAMERON, 1943: 127f

Type examined

Holotype +: Type [round curator label]/ Kashmir, Gulmarg, vi-vii-31, Dr. Cameron/ O. Kashmirica Cam., Type/ M. Cameron Bequest B. M. 1955-147. (BMNH).

Additional materiall examined

$2 \hat{\delta} \bar{\delta}, 3 \% q$, same data and collector as holotype (BMNH, cAss).

\section{Diagnosis}

Measurements (range; $\mathrm{n}=6$ ): HL: $0.74-0.80$; HW: $0.74-0.83$; PW: $0.80-0.83$; PL: $0.95-$ 0.98; EL: 0.53 - 0.59; TiL: 0.59- 0.65; TaL: 0.53 - 0.56; TL: 5.7 - 6.8.

In colour, size and proportions somewhat resembling the European O. subuliformis STEPHENS. Colour of head and abdomen brown to dark brown, pronotum and elytra \pm reddish brown, appendages yellowish to light brown. 


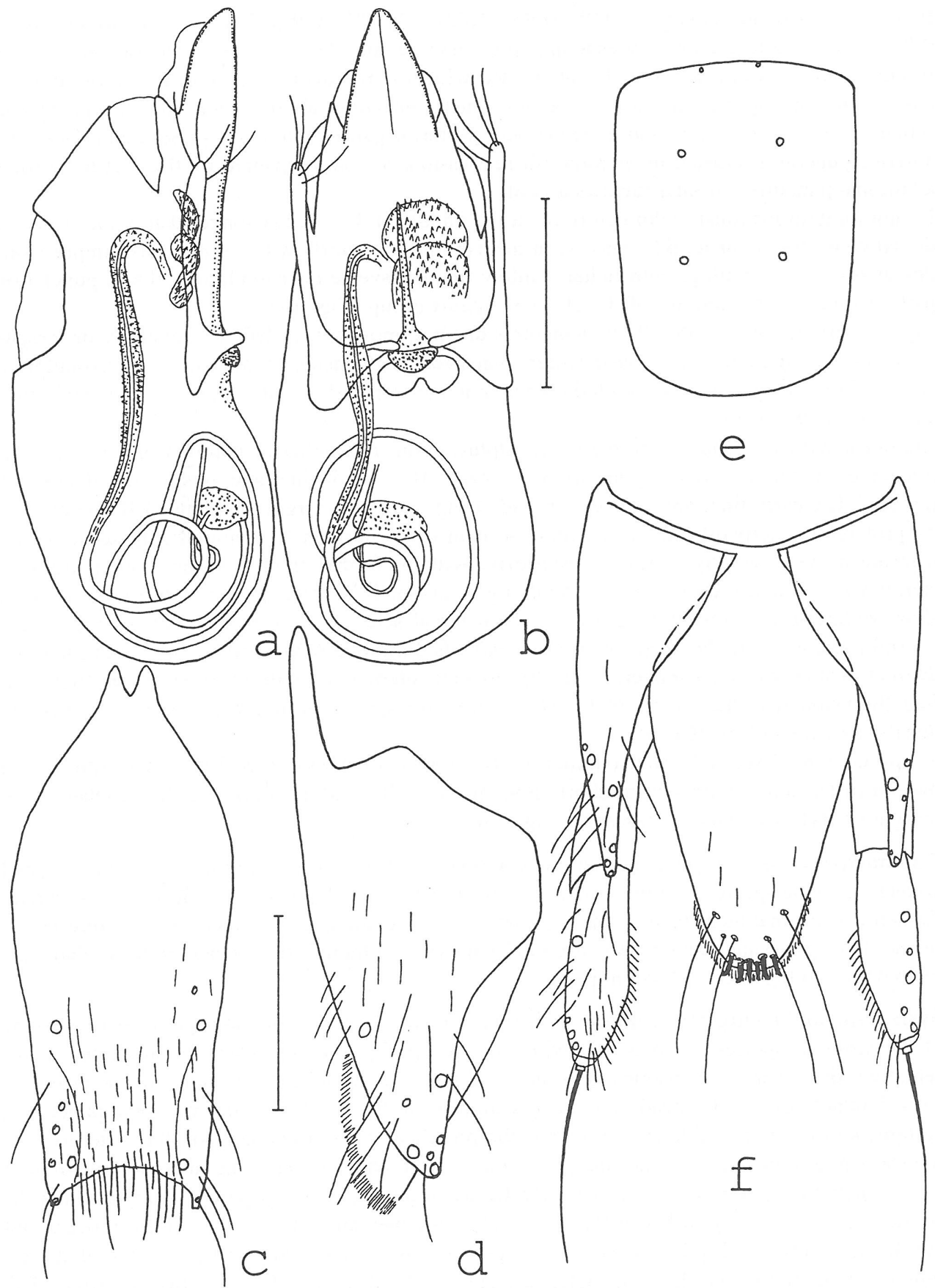

Fig. 16: O. kashmirica CAMERON: aedeagus in lateral (a) and in ventral view (b); $\delta$ sternum IX (c); $\delta$ lateral tergal sclerite IX and tergum X in lateral view (d); schematic representation of variability (left - right) of position of pronotal punctures (e); $q$ terminalia $(\mathfrak{f})$; setae partly omitted in $\mathrm{c}-\mathrm{f}$. Scales: $0.25 \mathrm{~mm}$ (e without scale). 
Head about as wide as long (HL/HW: 0.96 - 1.02); HW/PW: 0.91 - 1.04; eyes relatively large, $0.32-0.41 \mathrm{x}$ the length of postgenae in lateral view; temples behind eyes \pm parallel, straight or weakly convex in dorsal view; dorsal surface with fine but distinct transverse microsculpture, partly with interspersed transverse meshes; micropunctation absent; punctation of postgenae rather sparse and not very coarse; frons with posterior pair of punctures present and deep, the anterior punctures situated in \pm roundish impressions and accompanied by $0-2$ distinctly finer additional punctures; frontal furrows absent.

Pronotum with maximal width before or in the middle, $1.17-1.23 x$ longer than wide; sides in dorsal view straight or weakly convex; in median line posteriorly with a scratch-like impression; dorsal surface \pm shining, with rather shallow fine transverse microsculpture; discal punctation pattern similar to the species of the $O$. laeviusculus group (Fig. 16e).

Elytra short, EL/PL: 0.56 - 0.60; punctures distinct, mostly well-defined, regularly or irregularly spaced, interstices somewhat wider than average diameter of punctures; microsculpture absent; hind wings reduced; scutellum without punctures, but with shallow microsculpture; TiL/TaL: 1.08 - 1.23.

Abdomen with fine and transverse microsulpture, both near anterior margins of terga and on remainder of tergal surface; punctation on terga III - VI distinct and moderately dense, on tergum VII clearly finer and sparser; palisade fringe on hind margin of tergum VII absent.

$\delta$ : protarsi distinctly dilated, clearly more so than in $q$; sternum VII unmodified; sternum VIII truncate or very weakly concave posteriorly, without further modifications; hind margin of sternum IX \pm moderately concave, hind angles distinctly dentate, posterior median area with short yellowish pubescence (Fig. 16c); lateral tergal sclerites IX broadly pointed (Fig. 16d); ventral process of similar shape as in $O$. lapidicola MÄRKEL \& KIESENWETTER, with long and distinct median carina; parameres apically dilated; internal sac without sclerotized structures; flagellum similar to the species of the O. laeviusculus species group, wide, with 2-3 coils and distally darkened (Figs 16a, b).

\%: protarsi moderately dilated (similar to O. lapidicola MÄRKEL \& KIESENWETTER); hind margin of tergum $\mathrm{X}$ with several short, stout and apically slightly curved modified setae; inner margin of styli with short pubescence (Fig. 16f).

Comments: In his original description CAMERON (1943) only mentions a "Type in [his] collection". One specimen in the Cameron collection was identified as the holotype, as it carries Cameron's original identification and type label. The remaining 5 specimens are not referred to in the description and cannot be considered paratypes, although their labels indicate that they were collected together with holotype.

Systematic and comparative notes: $O$. kashmirica and the four following species belong to the O. laeviusculus species group as defined in AssING (1997). With the Western Palaearctic representatives they share such characters as the small to moderate size, the presence of the posterior frontal punctures on the head, the microsculpture of the forebody, the pronotal punctation pattern, the moderately dilated $q$ protarsi, the presence of modified setae on the $q$ tergum X, the short pubescence of the inner margin of the $q$ styli, and especially the internal structures of the aedeagus: the absence of distinctly sclerotized and oblong semitransparent structures, and the short, wide and distally darkened flagellum. The long median carina of the ventral process and the distinctly dilated $\delta$ protarsi seem to suggest a closer relationship to the species of the $O$. lapidicola subgroup, but these characters are apparently plesiomorphic (AssING, in press). The compressed apex of the ventral process, on the other hand, is here considered an apomorphy, which among Palaearctic Othius is only found in O. kashmirica and the four following species, and in the Othius lapidicola subgroup. The monophyly of $O$. kashmirica and related Himalayan 
congeners, hereafter referred to as $O$. kashmirica subgroup, is supported by both the presence of a wide, in lateral view $\pm S$-shaped transparent tube covered with short semitransparent spines and by the distribution. Species of this subgroup have become known only from the western parts of the southern Himalaya, from Kashmir ( 3 species) to central Nepal (3 species).

Distribution: 0 . kashmirica has become known only from the type locality.

Othius deharvengi COIFFAIT, 1982

Figs 17 a - d, Map 2 (p. 313)

Othius deharvengi CoIfFAIT, 1982a: 53f

\section{Type examined}

Holotype 9: versant SE Col de Ghorepani, 2150, 24.IX.77/ Holotype/ Othius deharvengi H. Coiffait 1979/ Muséum Paris 1985 Coll. H. Coiffait (MNHNP).

\section{Additional material examined}

$10^{\star}, 3$ 우, Nepal, Gurjakhani, $83^{\circ} 14^{\prime} \mathrm{E}, 28^{\circ} 37^{\prime} \mathrm{N}, 8,500 \mathrm{ft}$., 30.VI.1954, leg. Hyatt (BMNH, cAss); $10^{\star}$, Nepal, Mustang District, Thaksang, 3150m, Pinus excelsa-Abies-wood, Berlese, 26./29. IV.1980, leg. Martens \& Ausobsky (cAss).
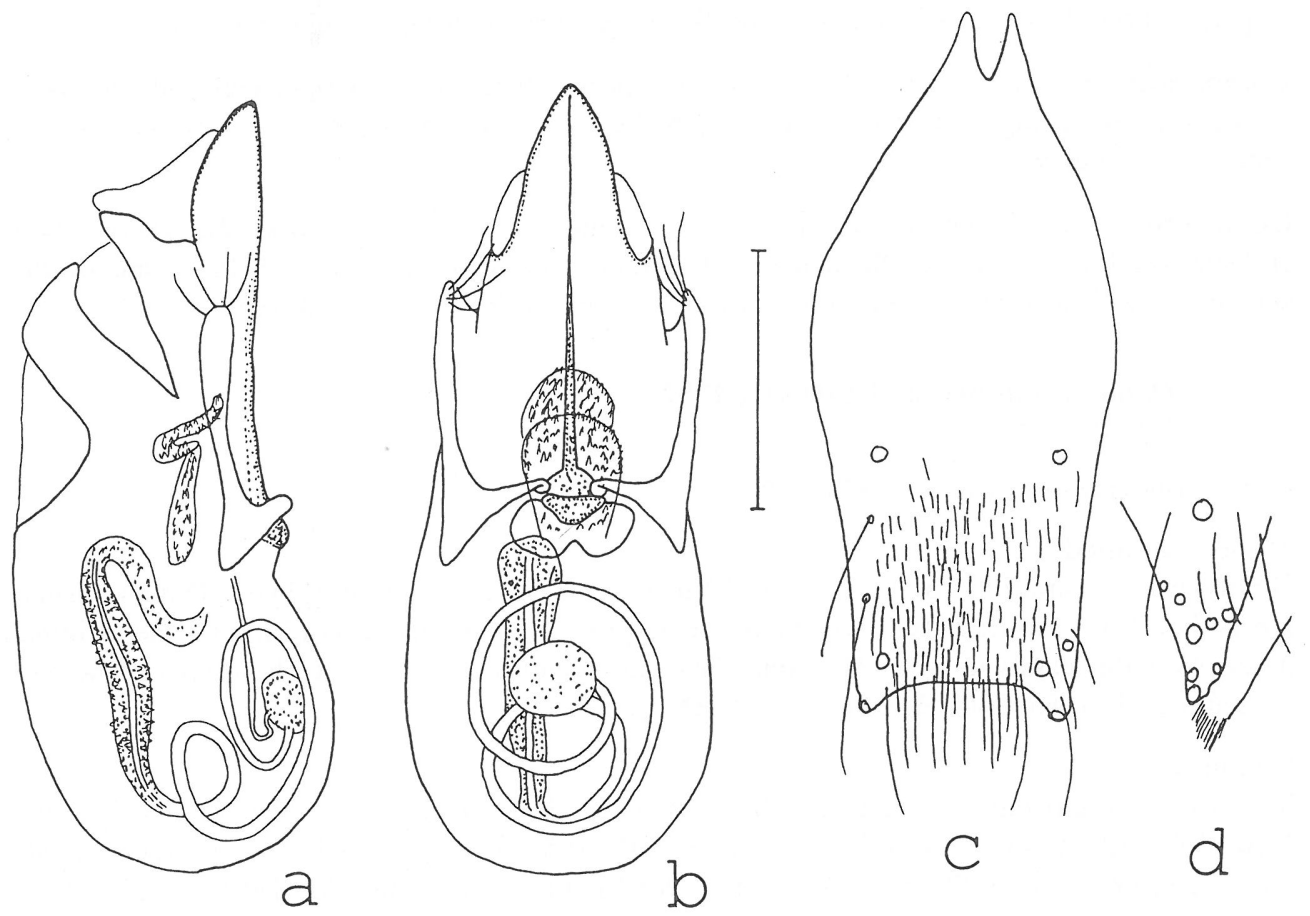

Fig. 17: $O$. deharvengi CoIfFAIT: aedeagus in lateral (a), in ventral view (b); $\delta$ sternum IX (c); posterior part of $\delta$ lateral tergal sclerite IX and tergum X in lateral view (d); setae partly omitted in $\mathrm{c}-\mathrm{d}$. Scale: $0.25 \mathrm{~mm}$.

\section{Diagnosis}

Measurements and ratios (range; $\mathrm{n}=6$ ): HL: $0.77-0.86$; HW: $0.72-0.80$; PW: $0.74-0.86$; PL: 0.92 - 1.07; EL: 0.56 - 0.63; TiL: 0.69- 0.76; TaL: $0.56-0.63$; TL: 5.8 - 6.6; HL/HW: 1.04 1.08; HW/PW: 0.92 - 0.98; PL/PW: 1.21 - 1.27; EL/PL: 0.55 - 0.62; TiL/TaL: $1.14-0.24$. 
Externally highly similar to and, apart from the longer legs, indistinguishable from the closely related $O$. kashmirica. Colour very variable, \pm brown to completely black. (It appears that the dark colour of some of the specimens may be the result of the influence of chemicals.)

$\delta$ : primary and secondary sexual characters as in $O$. kashmirica, but sternum VIII weakly convex, sternum IX with posterior median area more densely pubescent and posterior angles less distinctly dentate (Fig. 17c); lateral tergal sclerite IX as in Fig. 17d; aedeagus clearly smaller (Figs $17 \mathrm{a}-\mathrm{b}$ ).

$\%$ : terminalia as in 0 . kashmirica.

Comments: In spite of some external differences (coloration, size, punctation of elytra) and the slightly more acute apex of the ventral process in the $\delta$ from Gurjakhani, the specimens from Gurjakhani and from Thaksang are here referred to $O$. deharvengi for the following reasons. The description of the species is unfortunately based on a single female, so that in the absence of $\delta$ from the type locality, only circumstantial evidence can be considered. The differences observed were only slight, and the respective characters have been shown to be subject to considerable intraspecific variation in other species of Othius (AssING, 1997); based on the few specimens available, on the other hand, morphological variation in $O$. deharvengi cannot be adequately assessed. In addition, the three localities indicated above are all situated in central Nepal, and the degree of endemism in the O. kashmirica subgroup is unknown.

Comparative notes: From $O$. kashmirica, this species differs in the longer legs and especially in the smaller aedeagus. For distinction from the remaining congeners of the $O$. kashmirica subgroup see below.

Distribution: $O$. deharvengi is apparently an endemic of central Nepal (Map 2), where it was collected in May, June and September, at altitudes between 2150 and $3150 \mathrm{~m}$. One of the specimens was taken in a wood with Pinus excelsa and Abies as dominant trees.

Othius yusmargensis COIFFAIT, 1982

Figs $18 \mathrm{a}-\mathrm{d}$

Othius yusmargensis COIFFAIT, 1982b: 250f

Types examined

Holotype đ: Kashmir 1976, W. Wittmer/ Yusmarg, 5.7., 2300-2400m/ Type/ Othius yusmarensis [sic!] H. Coiffait 1981 (NHMB). Paratype $\delta$ [note that according to the original description the paratype is a 9 ]: same data and identification label as holotype/ Paratype/ Muséum Paris 1985 Coll. H. Coiffait (MNHNP).

\section{Diagnosis}

Measurements and ratios (HT, PT): HL: 0.75, 0.72; HW: 0.72, 0.69; PW: 0.83, 0.77; PL: 1.00, 0.97; EL: 0.56, 0.56; TiL: 0.65, 0.65; TaL: 0.53, 0.50; TL: 6.1, 5.2; HL/HW: 1.04 , 1.04; HW/PW: 0.87, 0.90; PL/PW: 1.21, 1.26; EL/PL: 0.56, 0.58; TiL/TaL: 1.23, 1.30.

Apart from the slightly narrower and slenderer head (see measurements) externally very similar to the closely related $O$. kashmirica. Eyes rather large, in lateral view $0.37-0.44 \mathrm{x}$ the length of temples.

ô: primary and secondary sexual characters (Figs 17c, d) as in $O$. kashmirica, but sternum VIII \pm truncate or weakly convex, aedeagus smaller, and ventral process apically more strongly compressed (Figs 17a, b).

\%: unknown. 


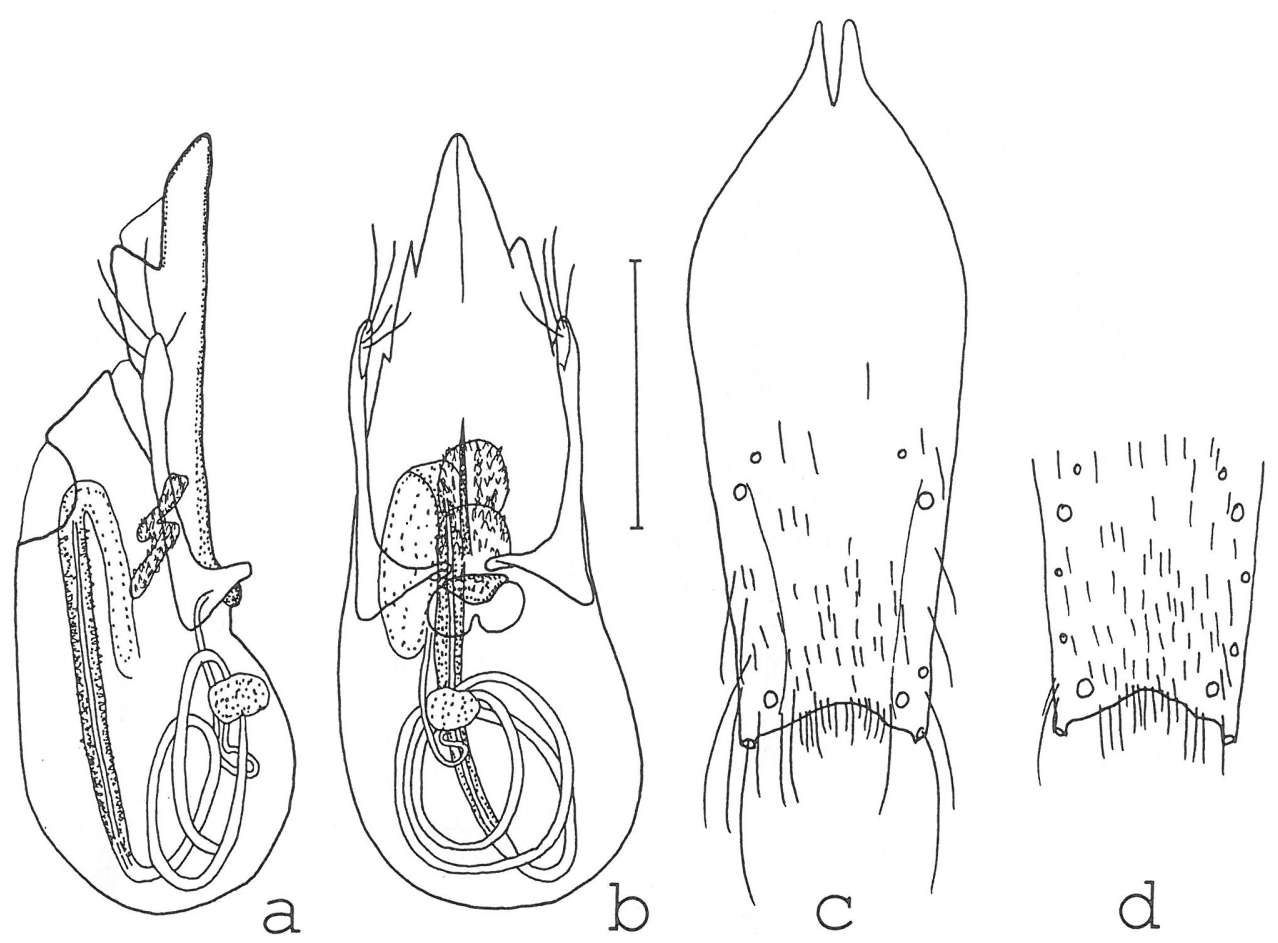

Fig. 18: O. yusmargensis CoIFFAIT (c: HT): aedeagus in lateral (a) and in ventral view (b); $\hat{o}$ sternum IX (c); posterior part of $\delta$ sternum IX of PT (d); setae partly omitted in c - d. Scale: $0.25 \mathrm{~mm}$.

Comparative notes: For distinction from $O$. kashmirica see above; from $O$. deharvengi, this species differs in the shorter legs (see measurements), the (on average) lower size, the more deeply concave hind margin and the more distinctly dentate hind angles of the sternum IX, and the less pronounced median carina of the ventral process of the aedeagus.

Distribution: 0 . yusmargensis has become known only from the type locality in Kashmir.

Othius cachemiricus COIFFAIT, 1982

Figs 19 a - d

Othius cachemiricus COIFFAIT, 1982b: 252

Type examined

Holotype $\delta$ [note that according to the original description the holotype is a 9 ]: Kashmir 1976, W. Wittmer/ Daksum, 9.-13.7., 2400-2700m/ Type/ Othius cachemiricus H. Coiffait 1981 (NHMB).

\section{Diagnosis}

Measurements and ratios (HT): HL: 0.66; HW: 0.60; PW: 0.65; PL: 0.83; EL: 0.53; TiL: 0.53; TaL: 0.47; TL: 6.1; HL/HW: 1.10; HW/PW: 0.93; PL/PW: 1.28; EL/PL: 0.64; TiL/TaL: 1.13 .

Externally similar to $O$. kashmirica, but distinctly smaller (see measurements), and elytral punctation very sparse, interstices on posterior half on average $>2 \mathrm{x}$ wider than punctures. 


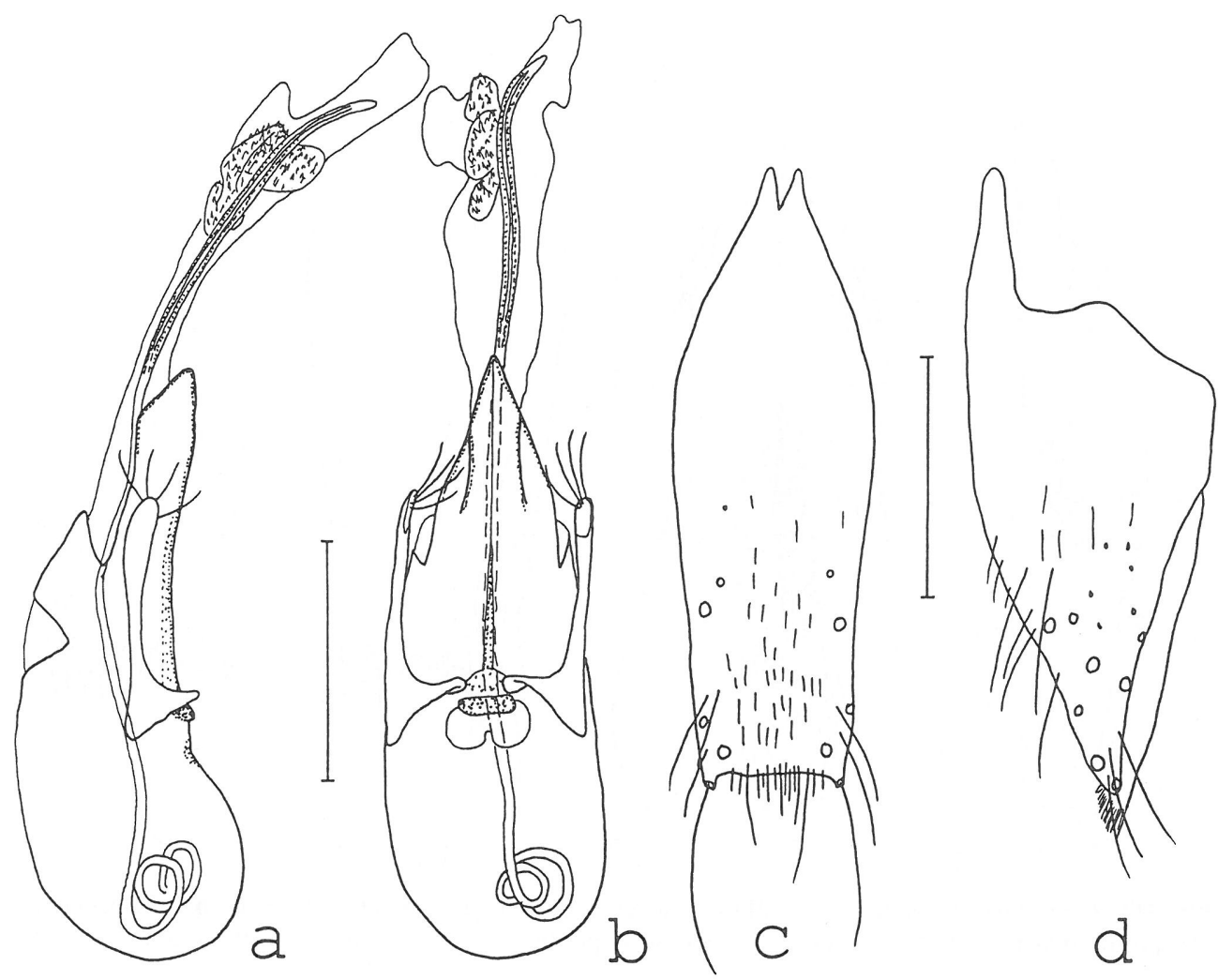

Fig. 19: O. cachemiricus CoIfFAIT (HT): aedeagus in lateral (a) and in ventral view (b); $\widehat{\delta}$ sternum IX (c); $\delta$ lateral tergal sclerite IX and tergum X in lateral view (d); setae partly omitted in $\mathrm{c}-\mathrm{d}$. Scales: $0.25 \mathrm{~mm}$.

$\delta$ : protarsi not distinctly dilated, approximately as wide as in the $q q$ of the related species; hind margin of sternum VIII distinctly convex; posterior margin of sternum IX centrally truncate (Fig. 19c); lateral tergal sclerite IX as in Fig. 19d; aedeagus smaller than in the related species (Figs 19a, b).

१: unknown.

Comparative notes: $O$. cachemiricus is readily distinguished from all the other species of the $O$. kashmirica subgroup by the smaller size and the 0 primary and secondary sexual characters.

Distribution: The species has become known only from the type locality in Kashmir.

Othius schawalleri sp. $\mathrm{n}$.

Figs 20 a - d, Map 2 (p. 313)

Holotype ठ̊: Nepal 464, Myagdi Distr., 1995, Myagdi Khola N Dobang, 2800-3100m, 22.24.V., Martens \& Schawaller (SMNS).

\section{Diagnosis}

Measurements and ratios (HT): HL: 0.95; HW: 0.92; PW: 0.98; PL: 1.15; EL: 0.61; TiL: 0.91;

TaL: 0.76; TL: 6.7; HL/HW: 1.03; HW/PW: 0.94; PL/PW: 1.17; EL/PL: 0.59; TiL/TaL: 1.20. 

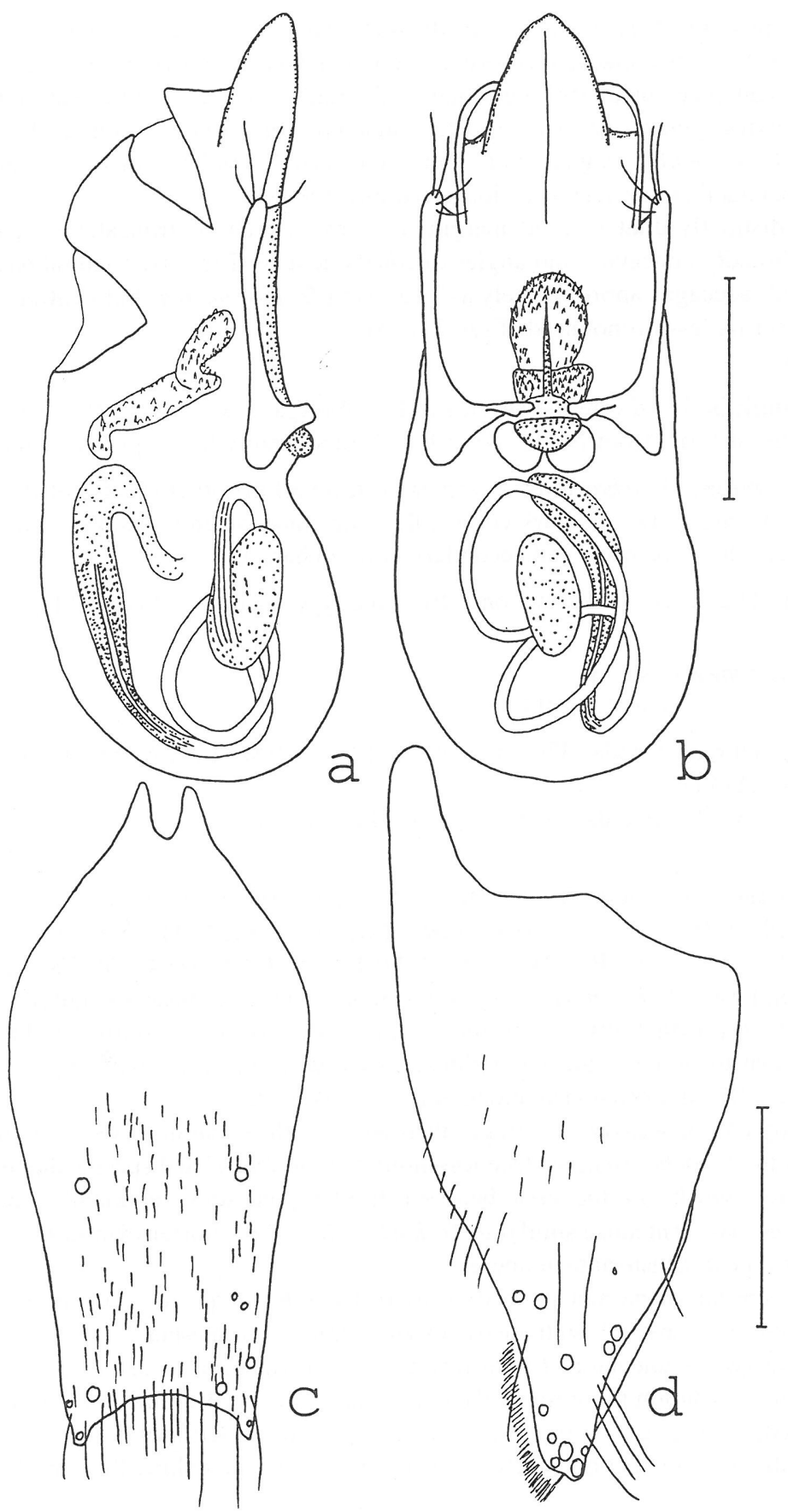

Fig. 20: O. schawalleri sp. n. (HT): aedeagus in lateral (a) and in ventral view (b); $\delta$ sternum IX (c); $\delta$ lateral tergal sclerite IX and tergum X in lateral view (d); setae partly omitted in c - d. Scales: $0.25 \mathrm{~mm}$. 
Externally similar to $O$. kashmirica, but distinctly larger (see measurements). Colour of body blackish, with the elytra blackish brown and the appendages, apart from the light brown tarsi, dark brown. Antennae distinctly longer than in the related species; penultimate antennomeres not transverse; elytral punctation characteristic: punctures of variable depth and size, irregularly spaced, partly somewhat rugose and with interspersed smaller punctures; surface therefore partly with subdued shine; legs very long (see measurements).

$\delta$ : protarsi distinctly dilated; hind margin of sternum VIII \pm truncate; posterior margin of sternum IX broadly concave, hind angles distinctly dentate (Fig. 20c); lateral tergal sclerites IX as in Fig. 20d; aedeagus approximately as large as in $O$. kashmirica, but ventral process broader and median carina less pronounced (Figs 20a, b).

\%: unknown.

Derivatio nominis: I dedicate the species to Dr. Wolfgang Schawaller (SMNS), who, through his remarkable material from Nepal, contributed considerably to the present study.

Comparative notes: $O$. schawalleri is separated from all the other species of the $O$. kashmirica subgroup by its larger size and dark colour, the long antennae and legs, the characteristic elytral punctation, and the $\delta$ primary and secondary sexual characters.

Distribution: The species is known only from the type locality in Nepal (Map 2).

Othius jaegeri sp. $\mathrm{n}$.

Figs 21 a - e, Map 2 (p. 313)

Holotype ơ: Telbrung Danda, 3700m, 9.VI./ NEPAL-HIMALAYA, SE-Annapurna mts., leg. O. Jäger 1997 (SMTD).

Paratypes: $10,3 q \uparrow$, same data as holotype (SMTD, cAss).

\section{Diagnosis}

Measurements and ratios (range; $n=5$ ): HL: $0.80-0.89$; HW: $0.76-0.86$; PW: $0.86-0.92$; PL: 1.03 - 1.09; EL: 0.60 - 0.66; TiL: 0.77- 0.80; TaL: 0.57 - 0.62; TL: 5.9 - 7.2; HL/HW: $1.02-$ 1.10; HW/PW: 0.86 - 0.98; PL/PW: 1.15 - 1.22; EL/PL: 0.57 - 0.64; TiL/TaL: 1.28 - 1.39.

Externally similar to $O$. kashmirica, but on average larger (see measurements). Colour of body dark brown to blackish brown, with the elytra, especially the margins, slightly lighter; legs yellowish brown to brown; antennae reddish brown with the apical part of antennomere II, all of antennomere III, and often also antennomere I darkened.

Head distinctly $(\delta)$ or weakly ( $(+)$ longer than wide, with \pm parallel postgenae in dorsal view; punctation as in $O$. kashmirica; surface less shiny than in the related species due to more distinct microsculpture, which, in the area between frontal punctures, is mainly composed of \pm isodiametric meshes. Antennae similar to O. kashmirica, i. e. shorter than in O. schawalleri and with transverse penultimate antennomeres.

Pronotum of similar shape and punctation as in the related species, but microsculpture more distinct and with interspersed isodiametric or short transverse meshes.

Elytra with surface \pm uneven and with irregular, \pm distinct microsculpture, less shiny than in $O$. kashmirica; punctation more regularly spaced and more well-defined than in $O$. schawalleri; hind wings reducecd. Legs of similar relative length as in $O$. kashmirica.

Abdomen with more distinct microsculpture and, therefore, less shine than in $O$. kashmirica.

Fig. 21: O. jaegeri sp. n. (a - b: HT; c-e: PT): aedeagus in lateral (a) and in ventral view (b); $\sigma^{3}$ sternum IX (c); $\delta$ lateral tergal sclerite IX and tergum $\mathrm{X}$ in lateral view (d); $q$ tergum $\mathrm{X}(\mathrm{e})$; setae partly omitted in c - d. Scales: $0.25 \mathrm{~mm}$ 


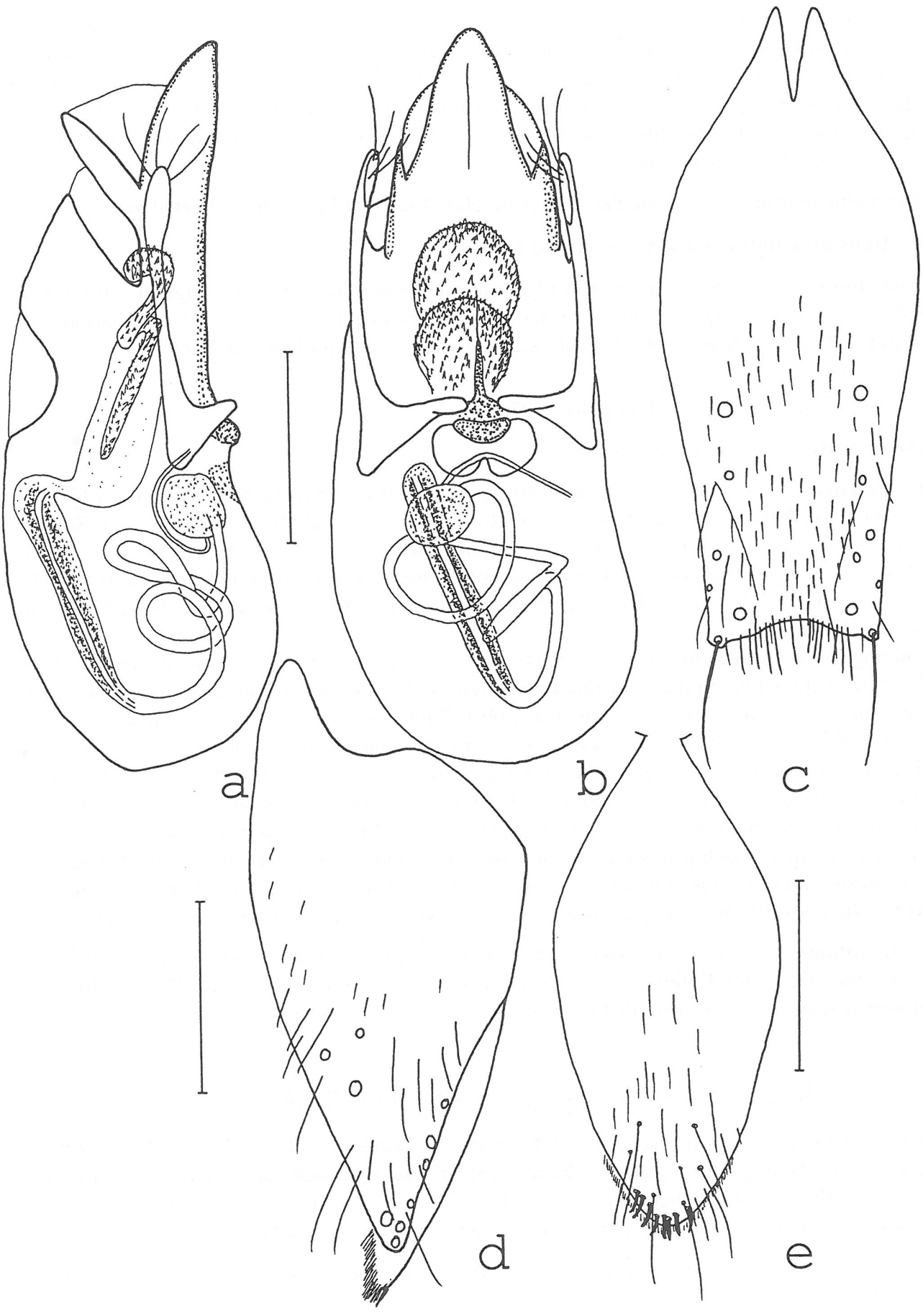


$\delta$ : protarsi strongly dilated; hind margin of sternum VIII \pm truncate; posterior margin of sternum IX weakly concave, \pm sinuate, hind angles weakly dentate (Fig. 21c); lateral tergal sclerites IX as in Fig. 21d; aedeagus of similar shape as in $O$. schawalleri, but relatively and absolutely larger, parameres longer and terminal part of flagellum darker (Figs 21a, b).

\$: protarsi distinctly less dilated than in $\delta$; tergum $\mathrm{X}$ slender, near hind margin with short and relatively stout modified setae (Fig. 21e).

Derivatio nominis: I dedicate the species to Olaf Jäger (SMTD), who collected the type series.

Comparative notes: see description and key.

Distribution: The species is known only from the Annapurna mountain range in central Nepal (Map 2), where - judging from the altitude of the type locality, the restricted distribution of the closely related congeners, and the reduced hind wings - it is probably endemic.

\section{Othius loeffleri Scheerpeltz, 1976}

Othius loeffleri Scheerpeltz, 1976b: 124f

Comments: The original description of this species is based on a single $q$ holotype, which was collected "in 3940 Höhe auf dem Beding, Rolwaling" in Nepal. In the introduction, SCHEERPELTZ (1976a) states that he received the material for his study from the "Bayerischen Staatssammlungen München". The holotype was looked for, but not found, neither in München nor in the Frey collection, which is now kept at the NHMB (BAEHR, in litt. 1997; SPRECHER, in litt. 1997).

Judging from the details indicated in the description regarding the pronotal punctation, $O$. loeffleri could belong to the $O$. kashmirica subgroup: "Außer den normalen Randpunkten finden sich nur die ... charakteristischen beiden groben Punkte jederseits der Mittellängslinie, im vordersten Viertel und im hintersten Viertel der Halsschildmittellänge je einer." On the other hand there is strong evidence suggesting that the species is closely related to the $O$. infestus species complex: the size $(8 \mathrm{~mm})$, the apparently absent posterior pair of frontal punctures on the head, and the distinct microreticulation of the elytra ("..., ihre Oberflächen sind von einer sehr dichten, rundnetzmaschigen Mikroskulptur bedeckt, dadurch fast ganz matt"). If $O$. loeffleri is a member of the $O$. infestus species complex, it could be a close relative of $O$. corniger, in which the posterior pronotal puncture is also somewhat distant from the posterior angles.

Distribution: Apart from the type locality, there are two further records by COIFFArT (1981) from "Barabinse; Mt Kalingchok, 3000 m" and from "Himal Chuli, Dudh Pokari, 3000 m", though it seems very unlikely that the corresponding specimens really refer to this species.

\section{Key to the Himalayan species of Othius STEPHENS}

Note that the key does not account for $O$. perreaui COIFFAIT and $O$. loeffleri SCHEERPELTZ. Both species belong to a complex of highly similar species, which can only be safely identified based on the $\delta$ sexual characters. Since their descriptions are based on single $q \uparrow$, a safe diagnosis is impossible until oे $^{\circ}$ from their respective type localities become available.

1. Pair of posterior frontal punctures present. Small species and one species of moderate size .............................. 2

- Pair of posterior frontal punctures absent. Large and moderately large species . . . . . 8 
2. Palisade fringe on abdominal tergum VII present; wing development polymorphic. Size larger (HL: >1.2; HW: >1.1; PW: >1.2; PL: >1.5; EL: >0.98; TL: > 8.0). Posterior discal puncture near hind angles of pronotum (Fig. 2e).

$\delta$ : aedeagus with 6 distinctly sclerotized structures in internal sac; apex of ventral process not compressed in ventral view; flagellum thin and with $>20$ coils (Figs $2 a, b$ ); secondary sexual characters as in Figs 2c, d.

: tergum X posteriorly with long modified setae; inner margin of styli with long, and anteriorly stout, apically bent setae (Fig. 2f).

Widely distributed in the southern Himalaya, from Himachal-Pradesh in the west to Sikkim

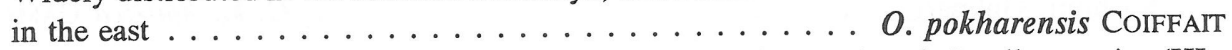
Palisade fringe on abdominal tergum VII absent; hind wings reduced. Smaller species (HL: $<1.0$; HW: <1.0; PW: <1.1; PL: <1.2; EL: <0.7; TL: <7.0). Posterior discal puncture at about $1 / 3$ of pronotal length from hind margin of pronotum (Fig. 16e).

$\delta$ : aedeagus without distinctly sclerotized structures in internal sac; apex of ventral process compressed in ventral view; flagellum wide and with $<4$ coils (e. g. Figs 16a, b); secondary sexual characters different.

ㅇ: tergum X posteriorly with short modified setae; inner margin of styli with short pubescence (Fig. 16f).

Locally endemic species in Kashmir and central Nepal. The O. kashmirica subgroup . . . 3

3. Larger species (HL: $>0.9$; HW: $>0.85$; PW: $>0.9$; PL: $>1.1$ ); legs and antennae more slender, penultimate antennomeres not transverse. Elytral punctures of variable depth and size, irregularly spaced, partly somewhat rugose and with interspersed smaller punctures; surface therefore with little shine.

$\delta$ : aedeagus and secondary sexual characters as in Figs $20 \mathrm{a}-\mathrm{d}$.

Central Nepal . . . . . . . . . . . . . . . . O. schawalleri sp. n.

- Smaller species (HL: <0.9; HW: <0.87; PW: <0.93; PL: <1.1); legs and antennae shorter, penultimate antennomere transverse. Elytral punctation \pm well-defined and \pm regularly spaced, interstices in most species without micropunctation and more shining.

$\delta$ : primary and secondary sexual characters different . . . . . . . . . . 4

4. Elytra with \pm uneven surface, with \pm distinct, irregular microsculpture, and with only little shine. Microsculpture on head, pronotum and abdomen more distinct; in the area enclosed by the two pairs of frontal punctures composed of \pm isodiametric meshes; central dorsal surface of pronotum usually with interspersed isodiametric and short transverse meshes.

$\delta$ : aedeagus relatively large (Figs 21a, b); secondary sexual characters as in Figs 21c, d. Central Nepal: Annapurna mountain range ............ O. jaegeri sp. $n$. Surface of elytra even, more shining, interstices at most with very indistinct micropunctation. Microsculpture finer and shallower; in the area enclosed by the two pairs of frontal punctures mainly composed of striae or long meshes; central dorsal surface of pronotum with transverse microsculpture throughout.

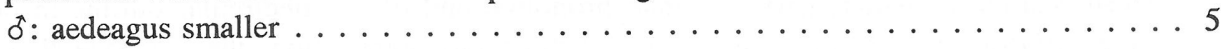

5. Smaller species (HL: <0.7; HW: <0.65; PW: <0.7; PL: <0.9).

o: protarsi not distinctly dilated; aedeagus small (Figs 19a, b); secondary sexual characters as in Figs 19c, d.

Kashmir: Daksum .................. o. cachemiricus CoIfFAIT Larger species (HL: >0.7; HW: >0.65; PW: >0.7; PL: >0.9).

$\delta$ : protarsi distinctly dilated; aedeagus larger . . . . . . . . . . . 6 
6. Species from central Nepal. Colour variable from \pm uniformly brown to blackish.

ơ: aedeagus and secondary sexual characters as in Figs $17 \mathrm{a}-\mathrm{d}$.

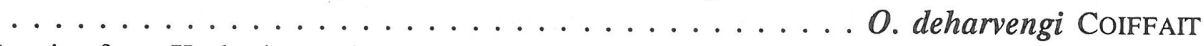

- Species from Kashmir. Body colour light brown . . . . . . . . . . . . . 7

7. $\delta$ : sternum VIII \pm truncate or weakly convex, aedeagus smaller (Figs 18 a - d).

Kashmir: Yusmarg ................. o. yusmargensis CoIfFArT

$\delta$ : sternum VIII truncate or very weakly concave posteriorly, aedeagus larger (Figs 16 a d).

Kashmir: Gulmarg .................... kashmirica CAMERON

8. Palisade fringe on abdominal tergum VII present. Larger species . . . . . . . . . . . 9

- Palisade fringe on abdominal tergum VII absent . . . . . . . . . . . . . 12

9. Very large species (HL: $>2.1$; HW: $>2.1$; PW: $>2.1$; PL: $>2.4$ ). Body, except for the dark brown tarsi and external face of the protibia, completely black. Elytra with distinct, but not very dense micropunctation.

\%: hind margin of sternum VIII with long black setae with interspersed short yellowish setae (Fig. 4b); tergum X posteriorly with numerous long black, unmodified setae (Fig. 4a).

Currently known only from Himachal-Pradesh, northwestern India

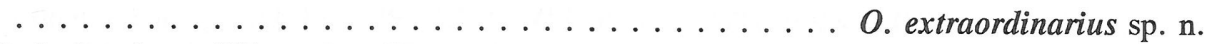

- $\quad$ Body less large (HL: <2.1; HW: <1.9; PW: <2.0; PL: <2.3); colour in some species dark, but not completely black. Micropunctation on elytra either absent or very sparse, or extremely dense.

: chaetotaxy of sternum VIII and tergum $\mathrm{X}$ different $\ldots \ldots \ldots \ldots$

10. Elytra dark brown to blackish, without micropunctation; pronotum very shiny, posterior half without microsculpture.

$\delta$ : aedeagus and secondary sexual characters as Figs $1 \mathrm{a}-\mathrm{f}$.

Widely distributed in the southern Himalayan region from Kumaun in the west to Sikkim and Meghalaya (northeastern India) in the east . . . . . . . o. apicalis CAMERON

- Elytra reddish, with either very sparse or very dense micropunctation; posterior half of pronotum with transverse microsculpture.

$\delta:$ primary and secondary sexual characters different $\ldots \ldots \ldots \ldots \ldots$

11. Head relatively large, at least as wide as pronotum (HL: $>1.8 ; \mathrm{HW}$ : $>1.6$ ) and of subrectangular outline in dorsal view. Elytra with very sparse, almost indistinct micropunctation. Pronotum with \pm straight lateral margins. Posterior margin of abdominal segment VII and following segments yellowish, strongly contrasting with the dark anterior abdominal segments; microsculpture of abdomen transverse.

$\delta$ : aedeagus and secondary sexual characters as in Figs 3 a - e.

Northern India and eastern Nepal . . . . . . . . . . . . flavocaudatus CAMERON

- Head relatively smaller, narrower than pronotum and of \pm subcircular outline in dorsal view. Elytra with extremely dense and distinct micropunctation, their surface therefore mat. Pronotum with slightly sinuate lateral margins. Apex of abdomen not strongly contrasting in colour with preceding segments; microsculpture of abdomen reticulate.

$\delta$ : sternum IX with sinuate hind margin and with numerous black setae in lateral posterior area (Figs 6c, d); aedeagus and further secondary sexual characters as in Figs 6a, b, e. Area south of Karakoram range . . . . . . . . . . O. sinuosus sp. n. 
12. Elytra shining, interstices without microsculpture.

§: aedeagus with 4 sclerotized structures of characteristic shape (Figs 5 a - c); secondary sexual characters as in Figs 5d, e.

Known only from Darjeeling, northeastern India

O. monticola CAMERON

Elytra with distinct microrecticulation and \pm mat.

$\delta$ : primary and secondary sexual characters different . . . . . . . . . . . 13

13. Larger species from Sikkim (HL: >1.6; HW: >1.4; PW: $>1.6$; PL: $>2.0$ ).

$\delta$ : aedeagus without basal median structure (Figs $7 \mathrm{a}, \mathrm{b}$ ); secondary sexual characters as in

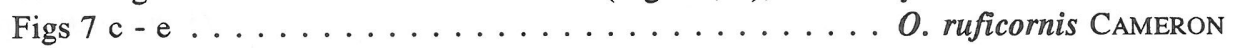

- Smaller species from central and eastern Nepal (HL: <1.6; HW: <1.4; PW: <1.6; PL: $>1.9$ ).

$\delta$ : aedeagus, except for 0 . corniger, with basal median structure . . . . . . 14

14. Smaller species (HL: <1.35; HW: <1.2; PW: <1.3; PL: <1.5); colour of body \pm uniformly brown.

Species from central Nepal and the Mt. Everest region . . . . . . . . . . 15

- Mostly larger species (HL: >1.25; HW: >1.15; PW: >1.25; PL: > 1.5); body at least partly (head, abdomen) darker. Species from eastern Nepal . . . . . . . . . . 16

15. Smaller species from the Mt. Everest region.

ठ: unknown

O. nepalensis (SCHEERPELTZ)

Slightly larger species from central Nepal.

$\delta$ : internal sac of aedeagus with characteristic internal structures: a very long median basal (longer than in any of the following species), a shorter median apical, and a pair of oblong lateral pieces (Figs 15a, b); secondary sexual characters as in Figs 15c, d . . . . . . .

O. longicuneatus sp. $\mathrm{n}$.

16. Head with microsculpture composed of distinct isodiametric meshes and mat; posterior discal puncture of pronotum clearly distant from hind angles (Fig. 14f).

$\delta$ : ventral process of characteristic shape both in ventral and in lateral view; internal sac with very characteristic internal structures: one median piece, a pair of short needle-like pieces and a pair of conspicuous structures resembling the antlers of a deer; basal median piece absent (Figs 14a - c); secondary sexual characters as in Figs $14 \mathrm{~d}$, e . . . . . . .

O. corniger sp. $\mathrm{n}$.

- Head with microsculpture less distinct and at least partly composed of transverse meshes and/or transverse striae; posterior discal puncture of pronotum close to hind angles.

$\delta$ : primary and secondary sexual characters different . . . . . . . . . . 17

17. $\delta$ : pair of lateral sclerotized structures very long; basal median structure longer than apical median structure (Figs 13a, b); flagellum with less than 15 coils; secondary sexual characters as in Figs $13 \mathrm{c}, \mathrm{d} \ldots \ldots \ldots \ldots$. . . . . . . . . . . . . . . .

- $\quad \delta$ : pair of lateral sclerotized structures distinctly shorter; basal median structure shorter than apical median structure; flagellum with 15 or more coils . . . . . . . . 18

18. Elytra more shiny, with weaker microsculpture, which is predominantly composed of fine and rather dense micropunctation rather than microreticulation; elytral punctures relatively large and distinct; dorsal surface of elytra very uneven; their posterior margin slightly bent downwards especially near posterior angles, posterior region therefore appearing somewhat convex. 
$\delta$ : hind margin of sternum IX \pm truncate (Fig. 12d); internal sac or aedeagus with apical median piece without distinct ventral tooth, basal piece in ventral view relatively broad and in lateral view with distinct median dilatation, and the pair of lateral pieces shaped like nails (Figs $12 \mathrm{a}-\mathrm{c}$ ) . . . . . . . . . . . . . . O. clavifer sp. $\mathrm{n}$.

- Microsculpture of elytra more distinct and microreticulate; dorsal surface less shiny and flatter.

$\delta:$ internal structures of aedeagus of different shape $\ldots \ldots \ldots \ldots$. . . . . . 19

19. 0 : hind margin of sternum IX \pm truncate (Fig. 11c); aedeagus with internal structures as in Figs $11 \mathrm{a}, \mathrm{b} \ldots \ldots \ldots \ldots \ldots \ldots$. truncatus $\mathrm{sp} . \mathrm{\ldots}$.

- $\delta$ : hind margin of sternum IX concave; aedeagus with internal structures of different shape ................................ 20

20. $\delta:$ median lobe of aedeagus smaller; lateral structures in internal sac very short (Figs 9a, b); secondary sexual characters as in Figs $9 \mathrm{c}, \mathrm{d} \ldots \ldots \ldots \ldots$. . . . acifer sp. n.

- $\delta$ : median lobe larger; lateral structures longer . . . . . . . . . . . . . . 21

21. Colour of body including elytra and appendages blackish brown to black; elytral surface uneven; elytral punctures larger.

$\delta$ : hind margin of sternum IX broadly and more shallowly concave, posterior median area with short and dense greyish pubescence (Fig. 8c); internal structures of aedeagus as in Figs $8 \mathrm{a}, \mathrm{b} \ldots \ldots \ldots \ldots \ldots \ldots$. . . . . . . . . . . . . . . . . .

- Colour of body lighter, especially the elytra reddish brown to brown; elytral surface more even, elytral punctures smaller.

$\delta$ : concavity of sternum IX deeper and more V-shaped, posterior median area with short and dense yellowish pubescence (Fig. 10c); internal structures of aedeagus as in

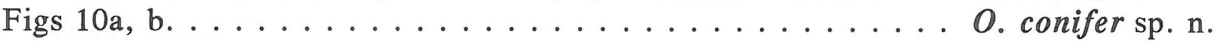

\section{A note on species diversity and phylogenetics}

In view of the fact that species number has doubled after the revision, although relatively little Othius material was available and examined, it seems certain that the species treated here represent only a very small fraction of the actual diversity of Othius in the Himalayan region and that many more species remain to be discovered. Most of the new taxa were collected at altitudes between 3000 and $4200 \mathrm{~m}$, apparently by sifting litter of natural Rhododendron and Abies woodland. 15 specimens collected by J. Martens and W. Schawaller in this habitat and at this altitude in the Taplejung District (eastern Nepal) alone belonged to 6 different species, all of them described here for the first time. (Two additional $q+$ are here neglected as no corresponding $\delta \delta^{*}$ were available.) If the litter layer in shrub and woodland biotopes above $3000 \mathrm{~m}$ in other Himalayan regions were intensively studied by sifting, the most appropriate collecting method for Othius, species number can be expected to increase significantly.

The Othius fauna of the southern Himalaya is composed of both Western and Eastern Palaearctic elements. The monophyletic $O$. kasmirica subgroup, currently comprising six species $(O$. kashmirica, $O$. yusmargensis, $O$. deharvengi, $O$. cachemiricus, $O$. schawalleri, $O$. jaegeri) from Kashmir and central Nepal, belongs to the Western Palaearctic O. laeviusculus species group; for a discussion of constituting characters and phylogenetic affiliations see comments below $O$. kashmirica. The remaining 18 species, on the other hand, are apparently of Eastern Palaearctic origin. With other Eastern Palaearctic species (three species from Japan and several species from China examined), they share such characters as the absence of the posterior pair of frontal 
punctures (exception: $O$. pokharensis), the pronotal punctation pattern, the general morphology of the aedeagus (especially the absence of a distinct median carina of the ventral process) and the structures of the internal sac (particularly the presence of median sclerotized structures). As the sister group of Othius and a suitable outgroup have not yet been identified, however, the polarities of these characters are not quite certain.

At present, it is not possible to fully assess the phylogenetic relationships within the Himalayan species of Eastern Palaearctic origin, as numerous further Othius species, especially from China, remain to be examined. The systematic position of $O$. sinuosus appears to be somewhat isolated, as it is distinguished from its Himalayan congeners by various relevant characters (see comparative notes below that species). Judging from the similarities in head shape, microsculpture of the forebody (especially of the elytra), wing development and the primary and secondary sexual characters, $O$. apicalis, $O$. flavocaudatus, $O$. extraordinarius and $O$. pokharensis are closely related; various external and sexual characters suggest that $O$. monticola, too, is a member of this species group, in spite of the reduced eye size, wings and palisade fringe (apparently adaptions associated with a higher altitude habitat) and its modified internal structures of the aedeagus. Similarly, the brachypterous species with distinct isodiametric microsculpture on the elytra $(O$. infestus and related congeners from eastern Nepal, $O$. nepalensis and O. longicuneatus from central Nepal, and possibly also O. ruficornis from Sikkim) seem to represent a monophyletic group, not only constituted by the probably apomorphic elytral microsculpture, but also by their bionomics (higher altitude habitats), their distribution, and the $\delta$ sexual characters (morphology of the aedeagus, internal structures). (Note that $O$. loeffleri, which may also belong here, is not included as it was not possible to locate the holotype, and because the description leaves some doubt regarding its affiliations.)

\section{References}

Assing, V. 1997: A revision of Othius STEPHENS, 1829 (Coleoptera, Staphylinidae: Xantholininae). III. The species of the Western Palaearctic region exclusive of the Atlantic Islands. - Nova Suppl. Ent. Berlin 10: 3-130.

Assing, V. in press: A revision of Othius STEPHENS of the Atlantic Islands. III: Further records, new species, phylogenetics, and colonization (Insecta, Coleoptera, Staphylinidae: Xantholininae). - Reichenbachia 32 (1998)

CAmERon, M. 1926: New species of Staphylinidae from India. - Trans. Ent. Soc. Lond. 1925: 341-372.

CAmeron, M. 1928: The Staphylinidae (Coleoptera) of the Third Mount Everest Expedition. - Ann. Mag. Nat. Hist., Ser. 10, 2: 558-569.

CAMERON, M. 1932: The fauna of British India, including Ceylon and Burma. Coleoptera. Staphylinidae. - Vol. III. - London: xiv +443 pp.

CAmERon, M. 1943: Descriptions of new Staphylinidae (Coleoptera). - Proc. R. Ent. Soc. Lond. (B) 12: 127-132.

CoIfFAIT, H. 1981: Staphylinides nouveaux du Népal. - Nouv. Rev. Ent. 11: 323-335.

CoIfFAIT, H. 1982a: Contribution à la connaissance des Staphylinides de l'Himalaya (Népal, Ladakh, Cachemire) (Insecta: Coleoptera: Staphylinidae). - Senckenbergiana biol. 62 (1981): 21-179.

CoIfFarT, H. 1982b: Staphylinides (Col.) de la région himalayenne et de l'Inde (I. Xantholininae, Staphylininae et Paederinae). - Entomol. Basiliensia 7: 231-302.

CoIfFAIT, H. 1983: Staphylinides du Massif du Ganesh Himal (Népal central) récoltés par Th. Deuve et E. Queinnec. Descriptions de nouvelles espèces et d'un nouveau genre himalayens. - Nouv. Rev. Ent. 13: $161-179$.

CoIffart, H. 1984: Contribution a la connaissance des Staphylinides de l'Himalaya (Coleoptera, Staphylinidae). - Annls Soc. ent. Fr. (N. S.) 20: 373-387. 
SCHEERPELTZ, O. 1976a: Wissenschaftliche Ergebnisse der von Prof. Dr. H. JANETSCHEK im Jahre 1961 in das Mt.-Everest-Gebiet Nepals unternommenen Studienreise (Col. Staphylinidae). - "Khumbu Himal" Ergebnisse des Forschungsunternehmens Nepal Himalaya 5: 3-75.

SCHEERPELTZ, O. 1976b: Wissenschaftliche Ergebnisse entomologischer Aufsammlungen in Nepal (Col. Staphylinidae). - "Khumbu Himal" Ergebnisse des Forschungsunternehmens Nepal Himalaya 5: 77-173.

\author{
Author's address: \\ VOLKER ASSING \\ Gabelsbergerstraße 2 \\ D-30163 Hannover \\ Germany
}

\title{
Besprechungen
}

Der Universitäts- und Forschungsstandort Deutschland im globalen Markt. Eine Publikation der Karl Heinz Beckurts-Stiftung / hrsg. von K. PINKAU; M. PoPp \& CH. STAHLBERG. - Stuttgart; Leipzig: Hirzel Verl., 1998. - 106 S. - 38.- DM

Dieser Band enthält die Vorträge des Symposiums der Karl Heinz Beckurts-Stiftung 'Universitäts- und Forschungsstandort Deutschland im globalen Markt', welches am 21./ 22.10.1996 in Bonn stattfand. Da die Forschungs- und Technologiepolitik mit der Diskussion um den Industriestandort Deutschland eine stärkere nationale Orientierung erhalten hat, setzte sich das Symposium mit den Aspekten der nationalen Forschungs- und Entwicklungspolitik gegenüber dem Trend zur Globalisierung der Märkte in der Wirtschaft auseinander.

Die Vorträge hatten zum Inhalt: Globalisierung der Forschung in pharmazeutischen Unternehmen (ERNSTGÜNTER AFTING), Wirtschaftspolitische und technologiepolitische Folgen der Globalisierung (HORST ALBACH), Die Zukunft der Universität (WOLFGANG FRÜHWALD), Universalismus und Globalisierung (CARL-FRIEDRICH GETHMANN), Ein europäisches System auf dem Weg zum globalen Erfolg (JOACHIM HAGENAUER), Internationale Kooperation in der Wissenschaft (KLAUS PINKAU), Differenzierung in der internationalen Kooperation (MANFRED POPP). Im Ergebnis des Symposiums kommt heraus, daß der globale Kenntnisaustausch in der Wissenschaft und das globale Agieren der Wirtschaft keine Gegensätze sind, wenn ein wechselseitiges Verständnis für das, was der Andere tut und warum er es tut, entwickelt wird. Andererseits besteht ein Nachholebedarf bei der Globalisierung bei gleichzeitiger Entwicklung des Industrie- und Forschungsstandortes Deutschland.

K. ROHLFIEN 